\title{
Non-linear deflection and stress analysis of laminated composite sandwich plate with elliptical cutout under different transverse loadings in hygro-thermal environment
}

https://doi.org/10.1515/cls-2020-0008

Received Apr 07, 2020; accepted Jun 25, 2020

Abstract: In this paper, non-linear transverse deflection, stress and stress concentration factors (SCF) of isotropic and laminated composite sandwich plate (LCSP) with and without elliptical cutouts subjected to various transverse loadings in hygrothermal environment are studied. The basic formulation is based on secant function-based shear deformation theory (SFSDT) with von-Karman nonlinearity. The governing equation of non-linear deflection is derived using $\mathrm{C}^{0}$ finite element method (FEM) through minimum potential energy approach. Normalized transverse maximum deflections (NTMD) along with stress concentration factor is determined by using Newton's Raphson method through Gauss point stress extrapolation. Influence of fiber orientations, load parameters, fiber volume fractions, plate span to thickness ratios, aspect ratios, thickness of core and face, position of core, boundary conditions, environmental conditions and types of transverse loading in MATLAB R2015a environment are examined. The numerical results using present solution methodology are verified with the results available in the literatures.

Keywords: laminated composite sandwich, cutout dimensions, transverse deflection, stress concentration factor

^Corresponding Author: Achchhe Lal: Department of Mechanical Engineering, S.V National Institute of Technology, Surat, India; Email: achchhelal@med.svnit.ac.in, lalachchhe@yahoo.co.in Rahul Kumar: Department of Mechanical Engineering, S.V National Institute of Technology, Surat, India;

Email: rahulkumar6289@gmail.com

B. M. Sutaria: Department of Mechanical Engineering, S.V National Institute of Technology, Surat, India; Email: bms@med.svnit.ac.in

\section{Abbreviations List}

$V_{f}$ and $V_{m} \quad$ fiber and matrix volume fraction

$A_{1 i j}, B_{i j}, C_{1 i j}, E_{i j}, F_{1 i j}, H_{i j}, A_{2 i j}, C_{2 i j}$ and $F_{2 i j}$

stiffnesses matrices

$a, b$

plate length and breadth along $\mathrm{x}$, $\mathrm{y}$ direction respectively

$h$ the thickness of the plate

$E_{f 1}$ and $E_{f 2}$ the elastic module of fiber material along the fiber and transverse direction

$v_{f 1}$ and $v_{f 2} \quad$ poission ratios of fiber material along the fiber and transverse direction

$\beta_{f 1}$ and $\beta_{f 2} \quad$ moisture coefficients of fiber along the fiber and transverse direction

$\alpha_{f 1}, \alpha_{f 2} \quad$ thermal expansion coefficients of fiber along $\mathrm{x}$ and $\mathrm{y}$-direction

$\alpha_{m}$ and $\mathrm{E}_{m} \quad$ thermal expansion coefficient and modulus of elasticity of matrix material

$\beta_{m}$ and $V_{m} \quad$ moisture coefficient and volume fraction of matrix material

$E_{1}$ and $E_{2} \quad$ modulus of elasticity along longitudinal and transverse direction of fiber

$\alpha_{11}$ and $\alpha_{22}$ thermal expansion coefficients of laminated reinforced composite along $\mathrm{x}$ and $\mathrm{y}$ direction

$v_{1} \quad$ Poisson ratio of composite

$\alpha_{1} \quad$ coefficient of thermal expansion of composite material

$\left[K_{l}\right] \quad$ linear bending stiffness matrix

$\left[K_{n l}\right] \quad$ non-linear stiffness matrices

$N E \quad$ number of elements

$N L \quad$ number of layers in laminates

$N_{i} \quad$ shape function of the $\mathrm{i}^{\text {th }}$ node

$v^{e} \quad$ displacement vector of eth element

$u_{0}, v_{0}$ and $w_{0}$ displacements of a point in the mid plane of the plate

$u, v$ and $w \quad$ displacement of a point along the $(\mathrm{x}, \mathrm{y}, \mathrm{z})$ co-ordinate axis 


\begin{tabular}{|c|c|}
\hline$\sigma_{i j}, \varepsilon_{i j}$ & stress vector, Strain vector \\
\hline$\theta_{y}, \theta_{x}$ & $\begin{array}{l}\text { rotations of normal to the midplane about } \\
\text { the } \mathrm{x} \text { and } \mathrm{y} \text {-axis respectively }\end{array}$ \\
\hline$\phi_{x}, \phi_{y}$ & slopes along $\mathrm{x}$ and $\mathrm{y}$-axis \\
\hline$x, y, z$ & cartesian coordinates \\
\hline$\left\{\varepsilon_{l}\right\},\left\{\varepsilon_{n l}\right\}$ & $\begin{array}{l}\text { the linear, non-linear strain, and thermal } \\
\text { strain vectors }\end{array}$ \\
\hline$B$ & geometrical matrix \\
\hline$\Delta T$ & increment in temperatures \\
\hline$\Delta C$ & increment in moisture \\
\hline$U_{l}, U_{n l}$ & $\begin{array}{l}\text { the linear, non-linear stain energy respec- } \\
\text { tively }\end{array}$ \\
\hline$[K]$ and $\{F\}$ & $\begin{array}{l}\text { total stiffness matrix and force vector, re- } \\
\text { spectively }\end{array}$ \\
\hline
\end{tabular}

\section{Introduction}

The laminated sandwich plates are being utilized in various industries with weight sensitive applications such as space vehicles, transportations, racing cars, boat hulls, marine and other offshore structures due to their superior strength and stiffness to weight ratio.

To further improve transverse rigidity against out plane deflection of the sandwich plate, reinforced composite laminates can be used in place of isotropic face sheet materials. Usually, cutouts are provided into these plates as in rooftop and different structures to permit passage of light, access to inner parts, venting and to upgrade openness of parts of the structure, fastening with different fragments and once in a while to avoid the resonance and optimum performance. These cutouts in the sandwich plate cause strength deprivation and hence to exploit their advantages, the suitable mathematical tools that deal with their infrequent behavior especially when weakened with cutouts, are imperious. Further effect of localised loading conditions like point load, line load, and patch load etc, with ecological conditions, such as temperature and moisture have extra criticalness on response of these plates and plays a significant role in designing for better reliability and performance. Stress concentration factor (SCF) around elliptical holes plays an important role for failure and fracture of the structures. The accurate evaluation of SCF is also helpful to improve optimum performance of structures.

Lots of research work are available for the bending analysis of laminated composite and sandwich plate with cutout. Paul and Rao [1, 2] analyzed laminated composite sandwich plate with circular cutout subjected to out plane loadings reveal stresses and SCF. Plate of length
(A) with circular hole od diameter (D) are analyzed by Jain [3] to investigate the effect of ratio (D/A), plate thickness and loading conditions on SCF. Laminated composite plate with finite dimensions having multiple cutouts is considered to investigate the influence of stacking sequence, distance between cutouts, and number of cutouts on SCF by XIWU et al. [4]. Rzayyig [5] analyzed influence of position of cutout of rectangular and square plates along the length and width on SCF, stress and displacement. Ukadgaonker and Rao [6] done analysis for distribution of stress around a hole in a plate subjected to in-plane loading and reveal the effect of shape of holes, nature of loadings and plate geometry. Toubal et al. [7] determined SCF near hole of carbon/epoxy composite plate experimentally and verified the outcomes with that of obtained by Lekhnitskii model. Patel and Sharma [8] done parametric study for failure strength and moment distribution and reveals the variation of these with ply layup, fiber orientation, corner radii, materials, loading angle. Composite plates with and without hole are analysed by Priyadharshani et al. [9] using FEM and ABAQUS and verified the results with experiments. Ram and Babu [10] investigated flexural behaviour of axisymmetric laminated panels using FEM based higher order shear deformation theory. Chaudhuri et al. [11] adopted same method for shell with different boundary conditions having reinforcement along margin of hole. Ghannadpour and Mehrparvar [12] developed a new method to determine effect of shape of hole, dimension and position on SCF of laminated composite plates with different boundary conditions. Zhou et al. [13] predict damage index for composite plates with hole and verified the results with experimental testing.

With the rise in applications of composite and sandwich plate, a rational analysis is also required for their optimum performance and during this course, different theories are developed and utilized by researchers for structural analysis of laminated composite plate under bending.

A new type of meshfree technique to discretize the third-order model of Reddy for orthotropic laminated plates and to predict the field variables very accurately was presented by Ferreira [14]. To analyze the structure of laminates with an equal thickness of laminae Ghosh and Dey [15] had considered four noded rectangular elements with seven independent variables. Higher-order plate theories are developed for out plane shear and large rotations in transverse bending of shear deformable composite plate. Cho and Parmerter [16], Putcha and Reddy [17] and Pandya and Kant [18] had considered all higherorder terms in formulation for non-linear deformation. A new non-polynomial generalized non-linear transverse 
shear deformation theory was presented and implemented based on the principle of virtual work for the structural response of laminated-composite and sandwich plate by Grover et al. [19, 20] and a number of numerical examples of composite and sandwich plates for the static and buckling responses were solved. Lal et al. [21] had analyzed to predict the behavior of the vibratory system of a laminated composite plate supported by an elastic foundation with lamina material properties and foundation stiffness parameters. A new trigonometric shear deformation theory which considers transverse shear strains along plate thickness and tangential stress-free boundary conditions was developed by Mantari et al. [22] which gives better results for 3D elastic bending for composite laminated and sandwich plates. Review of equivalent single layer and layerwise laminated plate theories presented by Reddy [23]. Sayyad et al. [24] had developed an analytical solution for bi-axial bending of isotropic, transversely isotropic, laminated composite and sandwich plates with transverse shear and normal effects by a sinusoidal shear and normal deformation theory. A triangular element shear deformation theory modeled on Reddy's higher-order shear deformation plate theory which is quite better in some cases but has few complexities with the satisfaction of inter-element connectivity requirement of the plate theory was presented by Sheikh and Chakrabarti [25]. A new plate theory was presented by Touratier [26] that accounts for cosine shear stress distribution and satisfy zero transverse shears at top and bottom of the plate with complexity as of the first order but gives better results and does not use shear correction factor. Failure analysis of thin laminated plates with even temperature growth by nonlinear finite element method based on Tsai-Wu failure criterion stresses has done to predict first-ply failure temperature by Srikanth and Kumar [27]. Maiti and Sinha [28] had developed a method based on finite element analysis to study the response of composite plates under bending, free vibration, and impact. An overview of available theories and finite elements developed for multilayered, composite plates and shell structure was paid attention by Carrera [29, 30]. Carrera and Valvano [31] used finite element based equivalent single layer, layer-wise and variable kinematic models for thermoelastic static analysis of laminated shell and accurately defined displacement and stress distribution along thickness of shell by combining refined model to Carrera Unified Formulation (CUF). They found that CUF is extremely useful in the thermomechanical analysis of composite shells. Carrera et al. [32] proposed finite element based new zig-zag power function depending on shell thickness for linear static stress analysis of laminated composite shell and carried out inves- tigation to check efficiency of the present shell element. The variable kinematic field is written by using continuous piecewise polynomial functions.

Tornabene et al. [33] proposed a mathematical model for damage analysis through a set of parametric studies in terms of displacement, stress and strain variation along thickness of laminated composite and sandwich structures. Tornabene et al. [34] done analytical and numerical comparative study of three and two dimensional spherical and doubly curved shell model in terms of displacements, stresses and strains of composite and sandwich plates subjected to transverse load. Tornabene et al. [35] used Carrera Unified Formulation for free vibration analysis of composite sandwich plates and doubly-curved shells having variable stiffness in which fiber orientation in top and bottom faces are along curvilinear path described by power law, sinusoidal, exponential, Gaussian and ellipse-shaped functions.

Composite and sandwich structures are frequently acted upon by various loading conditions and therefore the nature of loading is one of the key factors that must be considered for behavioral analysis of the plate. A proportional study of the sandwich plate with homogeneous and functionally graded material (FGM) core was carried out under point, uniformly distributed, patch, line, and hydrostatic loading to see the effect of FGM core on stress and transverse maximum deflection by Woodward and Kashtalyan [36].

The composite and sandwich structures are usually exposed to the ecological conditions during their functioning, therefore the influence of parameters like temperature and moisture must be examined for better safety and performance. Many research works have been done to demonstrate the effect of environmental conditions on response analysis of laminated composite plate. Analytical results based on Chebyshev series for the non-linear flexural response of hygro-thermo-mechanical loaded elastically supported thick laminated composite rectangular plates were presented by Upadhyay et al. [37]. Buckling characteristics of the laminated composite plate under hygro-thermo-mechanical loading were analyzed with $\mathrm{CO}$ FEM by Kumar et al. [38]. Non-linear static analysis of a piezoelectric sandwich plate with elastic foundation under hygro-thermo-mechanical loading was presented by Lal et al. [39] using (SFSDT) and revealed the effect of random system characteristics with fiber volume fraction, ply lay-up, geometry, boundary conditions, etc. on the transverse maximum deflection. Static analysis of a laminated sandwich plate with a soft compressible core was done by a proposed higher-order zig-zag theory. It is assumed that plane displacement varies cubically for both core 
and face sheets and transverse displacement as quadratically within the core but remains constant through the face by Pandit et al. [40]. Hadjiloizi et al. [41, 42] developed a micromechanical model and analyze smart composite piezo magnato-thermoelastic thin plate having varying thickness using three-dimensional formulation in PartI [41]. The effective elastic, piezo-electro-magnetic, dielectric permittivity, mechanical stress, electric displacement and magnetic induction are determined. While in Part-II [42] of their research work, the theory is presented using examples refer to thin laminated magnetoelectric plates of constant thickness and smart piezoelectric piezomagnetic composite plates.

From the literature survey, it is found that few works have been done by researchers on the analysis of laminated composite and sandwich plate with various cutout shape, but yet the effect of cutout dimension with various shapes on the transverse maximum deflection and stress of the LCSP is needed to be explored. Static analysis for bending of a sandwich plate with few certain types of loading (UDL, SSL) was reported but still limited work has been done with other types of loading like point load, line load, hydrostatic load and patch load. To the best of author's knowledge, effect of various parameters like stacking sequence, fiber orientation, loading conditions, span to plate thickness ratio, position of core, aspect ratio, fiber volume fraction, boundary conditions and cutout dimensions on the normalized transverse maximum deflection of a LCSP with elliptical cutout under induced temperature and moisture conditions were not investigated. In ad- dition to this, influence of thickness of face sheet and core of sandwich plate along with cutout is not addressed.

In the current analysis NTMD, stresses and SCF for LCSP with different elliptical cutouts under various type of transverse loading are investigated. The effect of stacking sequence, fiber orientation, loading conditions, length to plate thickness ratio, position of core, aspect ratio, thickness of face sheet and core, fiber volume fraction, boundary conditions, environmental conditions and cutout dimensions on NTMD, stresses and SCF are examined.

\section{Formulation}

The LCSP of span $a \times b$ and height $h$ as shown in Figure 1(a) is consider under bending. The thickness of the plate is divided into a thickness of core (hc) and face sheet (hf). The face is assumed as a laminated composite with stacking angle $\theta_{k}$, where $\mathrm{k}$ denotes layer of plates. The sandwich plate has an elliptical hole having major and minor axes diameters indicated by ma and mi respectively.

\subsection{Displacement fields}

Modified secant function shear deformation theory (SFSDT) based displacement field is proposed in this paper due to its high accuracy and less time taken in computation with the fewer unknown as compared to higher-order shear deformation theory. The displacement field on the basis of SFSDT at any point along principal axis direction

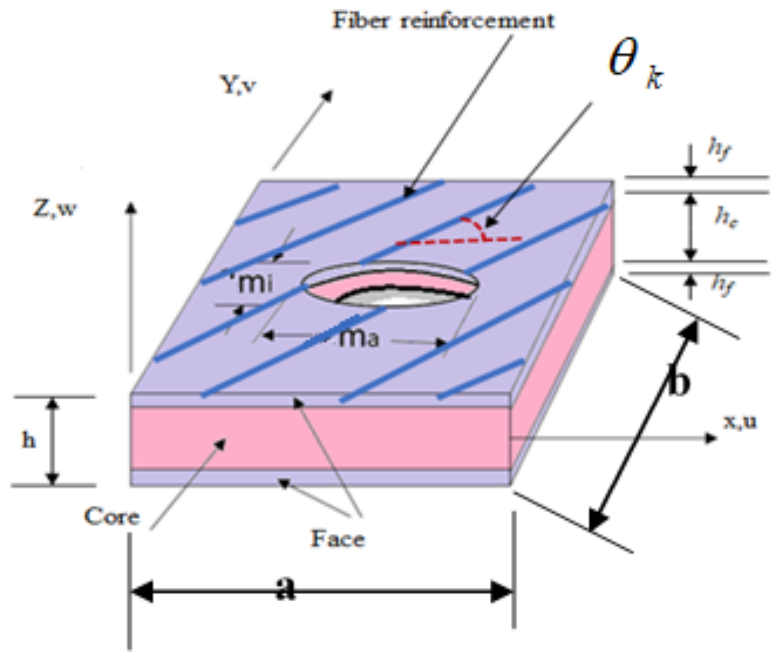

(a)

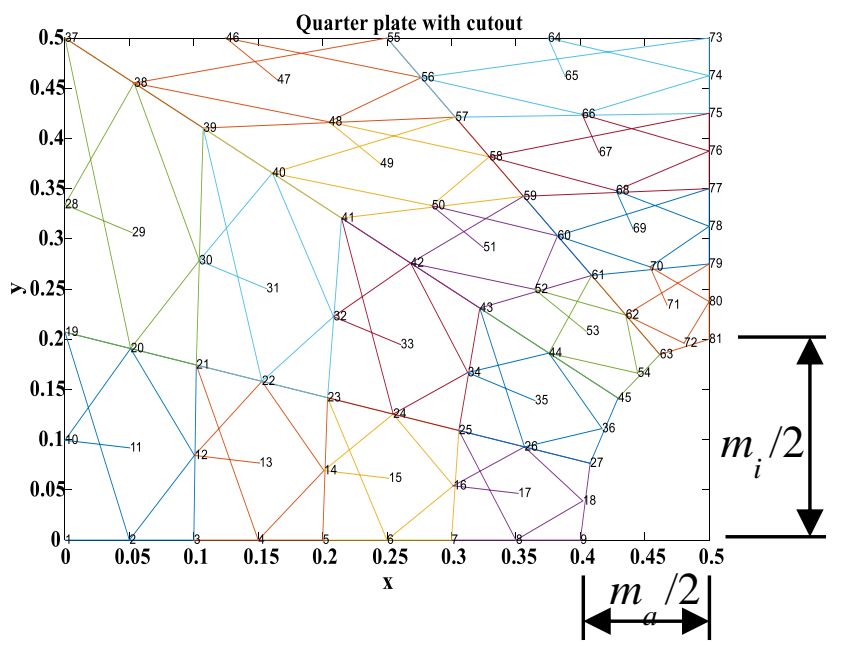

(b)

Figure 1: Laminated sandwich square plate with (a) elliptical cutout; (b) quarter part of elliptical cutout plate with FEM mesh 
can be given as [21].

$$
\begin{aligned}
& u=u_{0}-z \frac{\partial w_{0}}{\partial x}+\left(f(z)+z \mathrm{H}_{0}\right) \theta_{x} ; \\
& v=v_{0}-z \frac{\partial w_{0}}{\partial y}+\left(f(z)+z \mathrm{H}_{0}\right) \theta_{y} ; \quad w=w_{0}
\end{aligned}
$$

Where, $f(z)=z \sec \left(\frac{r z}{h}\right)$ is the shear strain function for SFSDT and $\mathrm{H}_{0}=-\frac{\sec \left(\frac{r}{2}\right)}{1+\frac{r}{2} \tan \left(\frac{r}{2}\right)}$ is a constant and its value can be determined by using zero transverse boundary conditions at outer surfaces. The value of transverse shear stress parameter ' $r$ ' can be determined by the reverse method. As Eq. (1) contains $\frac{\partial w_{0}}{\partial x}$ and $\frac{\partial w_{0}}{\partial y}$ therefore large computational effort is required to satisfy $\mathrm{C}^{1}$ continuity. To avoid this difficulty, two additional degrees of freedom $\phi_{x}=w_{0, x}$ and $\phi_{y}=w_{0, y}$ are introduced. Then new displacement fields and displacement vector can be written as

$$
\begin{aligned}
& u=u_{0}-z \phi_{x}+\left(f(z)+z H_{0}\right) \theta_{x} ; \\
& v=v_{0}-z \phi_{y}+\left(f(z)+z H_{0}\right) \theta_{y} ; \quad w=w_{0}
\end{aligned}
$$

and displacement vector can be written as

$$
\{\vee\}=\left(\begin{array}{lllllll}
u_{0} & v_{0} & w_{0} & \phi_{y} & \phi_{x} & \theta_{y} & \theta_{x}
\end{array}\right)^{T}
$$

\subsection{Strain displacement relations}

When a large load is applied, structural stiffness changes due to large deformation and therefore geometrical nonlinearity must be considered. Von-Karman nonlinearity has considered in the present paper with large displacement assumption. The strain vectors for the displacement of laminae can be given as [21].

$$
\{\varepsilon\}=\left\{\varepsilon_{0}\right\}+\left\{\varepsilon_{n l}\right\}
$$

Where $\left\{\varepsilon_{0}\right\}$ and $\left\{\varepsilon_{n l}\right\}$ are linear and nonlinear strains respectively.

\subsection{Properties of face sheet material}

The micromechanical approach is utilized in the current paper to decide the material characteristics of the reinforced composite face sheet of LCSP at induced ecological conditions. Influence of temperature on matrix material is more significant hence the same on the composite material can be referred to as that of the matrix material. The properties retention ratio for the matrix is given as [39]

$$
R_{m}=\left[\frac{t_{w}-t}{t_{d}-t_{\text {env }}}\right]^{\frac{1}{2}}
$$

Where, $t$ is the temperature at which properties of a composite laminate is to be estimated, $t_{d}, t_{e v n}$ and $t_{w}$ are glass transition temperature for dry condition, reference environmental temperature and glass transition temperature at wet conditions respectively.

Using the micromechanical approach, the elastic constants of reinforced composite face sheet can be given as [39]

$$
\begin{gathered}
E_{11}=E_{f 1} V_{f}+R_{m} E_{m} V_{m} \\
E_{22}=\left(1-\sqrt{V_{f}}\right) R_{m} E_{m}+\frac{R_{m} E_{m} \sqrt{V_{f}}}{1-\sqrt{V_{f}}\left(1-\frac{R_{m} E_{m}}{E_{f 2}}\right)} \\
G_{12}=\left(1-\sqrt{V_{f}}\right) R_{m} G_{m}+\frac{R_{m} G_{m} \sqrt{V_{f}}}{1-\sqrt{V_{f}}\left(1-\frac{R_{m} G_{m}}{G_{f 12}}\right)} \\
v_{12}=v_{f 12} V_{f}+v_{m} V_{m}
\end{gathered}
$$

Where ' $f$ ' and ' $m$ ' are subscript used for fiber and matrix material of composite face. The matrix thermal property can be estimated with a thermal characteristics retention ratio given as

$$
F_{t h}=\frac{1}{F_{m}}
$$

The thermal expansion coefficients using a micromechanical approach can be written as Kumar et al. [9]

$$
\begin{gathered}
\alpha_{11}=\frac{E_{f 1} V_{f} \alpha_{f 1}+F_{m} E_{m} V_{m} F_{t h} \alpha_{m}}{E_{f 1} V_{f}+F_{m} E_{m} V_{m}} \\
\alpha_{22}=\left(1+v_{f 12}\right) V_{f} \alpha_{f 2}+\left(1+v_{m}\right) V_{m} F_{t h} \alpha_{m}-v_{12} \alpha_{11}
\end{gathered}
$$

\subsection{Constitutive equation}

The constitutive equation for $k^{\text {th }}$ orthotropic lamina is a relation among stress, strain, and elastic constants and can be written as [39]

$$
[\sigma]=\left[\overline{Q_{k}}\right]\{\varepsilon\}
$$

Where $\left[\bar{Q}_{k}\right]=\left[Q_{c}\right]$ for $\mathrm{k}=3$ (defined in Appendix A-3) and $\left[\bar{Q}_{k}\right]=\left[Q_{f}\right]$ for $\mathrm{k}=1,2,4$ and 5 (calculated using micromechanical approach) are reduced constitutive elastic stiffness matrices for core and face sheet materials respectively in case of five-layer LCSP. 


\subsection{Stress concentration factor (SCF)}

Plate with geometrical discontinuities like hole and notches is generally used as structural member. Any such irregularity in a structural member influences the stress distribution in the nearby area and acts as stress raiser. The ratio of stress at a point on the circumference of cutout to the stress at the same point without cutout is known as SCF and can be given as

$$
\mathrm{SCF}=\frac{\text { Stress at a pointonthecircumferenceofcutout }}{\text { stress at the same pointwithoutcutout }}
$$

\subsection{Strain energy of LCSP}

The strain energy of LCSP can be expressed as

$$
\begin{aligned}
U & =\frac{1}{2} \sum_{k=1}^{N L} \int_{V}\left(\left(\varepsilon_{0}+\varepsilon_{n l}\right)^{T}\left[\overline{Q_{k}}\right]\left(\varepsilon_{0}+\varepsilon_{n l}\right)\right) d V \\
& =\frac{1}{2} \sum_{k=1}^{N L} \int_{V}\left(\varepsilon_{0}\right)^{T}\left[\overline{Q_{k}}\right]\left(\varepsilon_{0}\right) d V \\
& +\frac{1}{2} \sum_{k=1}^{N L}\left[\int_{V}\left(\varepsilon_{0}\right)^{T}\left[\overline{Q_{k}}\right]\left(\varepsilon_{n l}\right)+\int_{V}\left(\varepsilon_{n l}\right)^{T}\left[\overline{Q_{k}}\right]\left(\varepsilon_{0}\right)\right. \\
& \left.+\int_{V}\left(\varepsilon_{n l}\right)^{T}\left[\overline{Q_{k}}\right]\left(\varepsilon_{n l}\right)\right] d V
\end{aligned}
$$

Where, $k$ denotes layer of LCSP.

On substituting displacement vector and kinematic matrix, the expression for strain energy can be written as

$$
\begin{aligned}
U & =\frac{1}{2} \int_{A}\left(\vee^{T} L^{T} D L \vee\right) d A \\
& +\frac{1}{2} \int_{A}\left(\vee^{T} L^{T} D_{2} A \phi+A^{T} \phi^{T} D_{3} \vee L+A^{T} \phi^{T} D_{4} \phi\right) d A
\end{aligned}
$$

Where $[L]$ is kinematic matrix (given in Appendix A-2), D is system linear elastic stiffness matrix and $D_{2}, D_{3}$ and $D_{4}$ are nonlinear elastic stiffness matrices of system defined in Appendix A-4.

\subsection{Finite element method-based solution}

FEM is an efficient technique to find an approximate solution for bending problem with complex boundary conditions and geometry. The displacement vector can be written as

$$
\{\vee\}=\sum_{i=1}^{N N}\left[N_{i}\right]\left\{\vee_{i}\right\}
$$

Where $i$ denotes node number and $N_{i}$ is shape function at $i^{\text {th }}$ node. The strain displacement matrix $[B]$ for the plate can be expressed as

$$
\begin{aligned}
& {[B]=[L]\left[N_{i}\right] \quad \text { with } \quad[B]=\left[B_{1}, B_{2}, \ldots, B_{N N}\right]} \\
& \text { and }\left[B_{i}\right]=[L] N_{i} \quad(i=1, \ldots, N N)
\end{aligned}
$$

Using finite element model modified strain energy can be expressed as

$$
\begin{aligned}
U & =\sum_{i=1}^{N E}\left(\vee^{T} K_{0} \vee\right) \\
& +\sum_{i=1}^{N E}\left\{\left(\vee^{T} K_{1} \vee\right)+\left(\vee^{T} K_{2} \vee\right)+\left(\vee^{T} K_{3} \vee\right)\right\}
\end{aligned}
$$

Where $K_{0}=\sum_{k=1}^{N L} \frac{1}{2} \int_{A} B^{T} D B d A$, is a summation of linear element stiffness matrix for different layers of the plate and $K_{1}=\frac{1}{2} \sum_{k=1}^{N L} \int_{A} B^{T} D_{3}\{A\}\{\phi\} d x d y$, $K_{2}=\frac{1}{2} \sum_{k=1}^{N L} \int_{A}\{A\}^{T}\{\phi\}^{T} D_{4} \mathrm{~B} d x d y$ and $K_{3}=\frac{1}{2} \sum_{k=1}^{N L} \int_{A}\{\phi\}^{T}\{A\}^{T} D_{5}\{\mathrm{~A}\}\{\phi\} d x d y$ are the nonlinear element stiffness matrix.

Potential energy $(\Omega)$ due to work done by mechanical loading can be given as

$$
\Omega=\sum_{i=1}^{N E}\{\bigvee\}^{T} F,
$$

Where $F=\left(\begin{array}{llllll}0 & 0 & q o & 0 & 0 & 0\end{array}\right)^{T}$ is force vector and $q 0$ is input load parameter.

Using Gauss point integration, bending stiffness matrix can be determined by transforming elemental coordinate to that of Gauss quadrature element.

\subsection{Governing equation for bending}

The governing equation for the nonlinear static study can be expressed by utilizing the principle of virtual displacement as

$$
\frac{\partial \prod}{\partial \bigvee^{T}}=0
$$

Where

$$
\prod=U+\Omega
$$

The governing equation can be written as

$$
[K]\{\vee\}=[F]
$$


Where $[F]$ is the external force vector and $[K]$ is overall stiffness matrix, further written as

$$
[K]=\left\{K_{l}+K_{n l}\right\}
$$

Where $\left[K_{l}\right]$ and $\left[K_{n l}\right]$ are overall linear and nonlinear stiffness matrices.

\subsection{Solution approach}

Due to less computational effort and fast convergence the Newton Raphson method is utilized to solve the governing equation of bending (equation-19) as

$$
[K](\{\vee\})\{\vee\}=[F]
$$

Now residual vector for the above equation is written as

$$
R\{\vee\}=K(\{\vee\})\{\vee\}-\{F\}=0
$$

By assuming initial solution residual vector can be expanded using Taylor's series and after neglecting higher order terms starting from second order equation (22) can be given as

$$
\begin{aligned}
K_{T}\left(\{\vee\}^{i-1}\right) \delta\{\vee\} & =-R\left(\{\vee\}^{i-1}\right) \\
& =\left\{F^{\star}\right\}-K\left(\{\vee\}^{i-1}\right)\{\vee\}^{i-1}
\end{aligned}
$$

Where, $\left[K_{T}\left(\{\vee\}^{i-1}\right)\right]=\left(\frac{\partial R(\{\vee\})}{\partial\{\vee\}}\right)^{i-1}$ is tangent stiffness matrix.

The new displacement vector for $\mathrm{i}^{\text {th }}$ iteration can be expressed as

$$
\{\vee\}^{i}=\{\vee\}^{i-1}-\left[K _ { T } ( \{ \vee \} ^ { i - 1 } ] ^ { - 1 } R \left(\{\vee\}^{i-1}\right.\right.
$$

This process is continued till the two consecutives iterative values approaches less than a predetermined tolerance value.

After determining deflection, post-processing steps of FEM can be used to compute Gauss point stresses at any node (i) of the element using Eq. (10), and Eq. (14) is expressed as

$$
\left[\sigma_{i}\right]^{\mathrm{e}}=\left[\overline{Q_{k}}\right]\left[\mathrm{B}_{\mathrm{i}}\right]\left\{\vee_{i}\right\}^{\mathrm{e}}
$$

The strain displacement matrix $[\mathrm{B}]$ contains derivatives of interpolation with respect to Gauss element coordinates of the nodal point at which stress is to be evaluated in the element. This process is repeated in a loop for all the elements of LCSP and Gauss point stresses are computed. Corresponding stresses at element nodes $\sigma_{i, e p}$ can be extrapolated by using Gauss point stress and shape function as

$$
\left\{\sigma_{i, e p}\right\}^{\mathrm{e}}=\left[\mathrm{N}_{\mathrm{i}}^{\prime}\right]\left\{\sigma_{i}\right\}^{\mathrm{e}}
$$

$$
\text { for } i=1,2,3,4,5,6,7,8 \text { and } 9
$$

Where $\left[\mathrm{N}_{\mathrm{i}}^{\prime}\right]$ are shape functions with Gauss element coordinates replaced with natural coordinates using proportionality factors.

\section{Results and discussion}

By using proposed formulation and solution approach, an FEM based MATLAB code is generated for bending analysis of LCSP with and without elliptical hole. The plate is discretized using nine noded iso-parametric quadrilateral element with seven degrees of freedom at each node. The NTMD and stresses are calculated for various input parameters and outcomes are compared to published results. The linear values are written in brackets, unless otherwise stated.

Stress concentration factors for $\sigma_{x}$ and $\sigma_{y}$ are determined for various cutouts of LCSP at top of first layer and SCF for $\tau_{x y}$ is evaluated at bottom of the first layer at a point on the circumference of cutout. The effects of support conditions, fiber orientation, ecological conditions and span to thickness ratio are examined. The cutouts for the present work are considered as

$m_{a}=0.2, m_{i}=0.1$ as cutout case $1, m_{a}=0.4, m_{i}=0.1$ as cutout case 2

$m_{a}=0.6, m_{i}=0.1$ as cutout case $3, m_{a}=0.1, m_{i}=0.2$ as cutout case 4

$m_{a}=0.1, m_{i}=0.4$ as cutout case $5, m_{a}=0.1, m_{i}=0.6$ as cutout case 6

and $m_{a}=0.5, m_{i}=0.5$ as cutout case 7

While applying the above boundary conditions for a plate with cutout, an equivalent quarter portion of the plate is considered. Finite element mesh of quarter portion of the plate is shown in Figure 1(b). No constraints on the arc of cutout were considered while applying boundary conditions.

Sandwich plates are usually acted upon by different types of loading during their functioning in various applications therefore many types of loading (UDL, SSL, Point load, hydrostatic load, patch load and line load) has been considered here in this paper to estimate transverse deflection.

Types of loading shown in Figure 3(a-f) and their normalization used for current results can be written as

Uniformly distributed load (UDL):

$q_{u d l}=q 0(x c \times y c) E_{2}(h / a)^{4}$ 


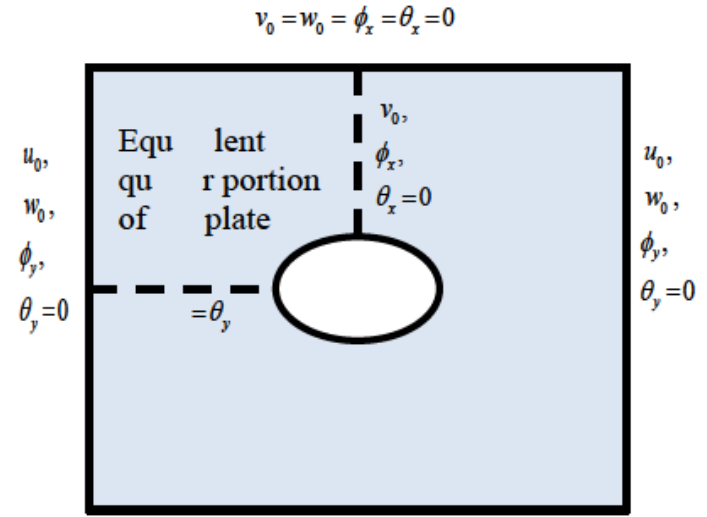

$$
w_{0}=\phi_{x}=\theta_{x}=0
$$

(a)

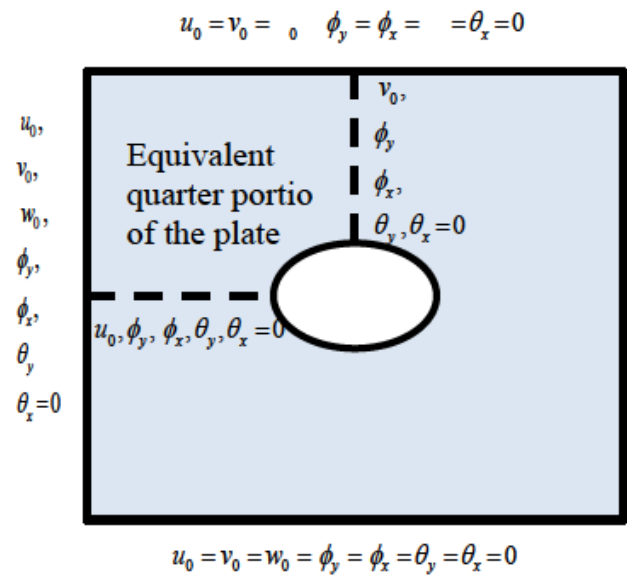

(c)

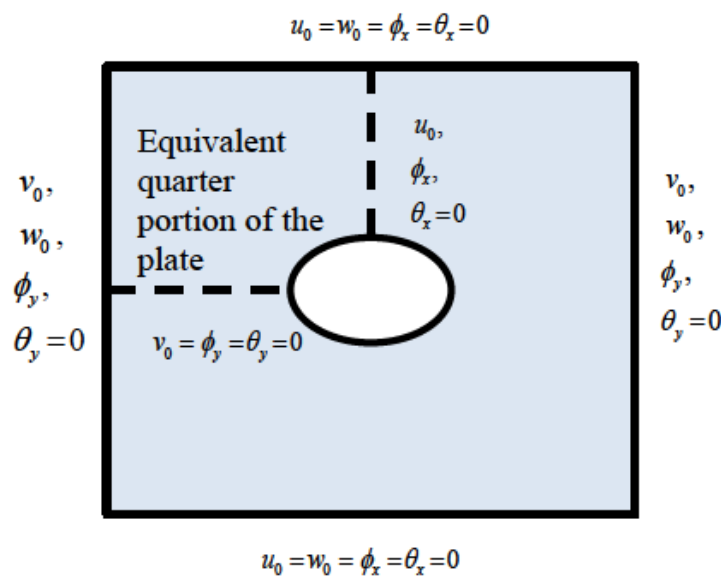

(b)

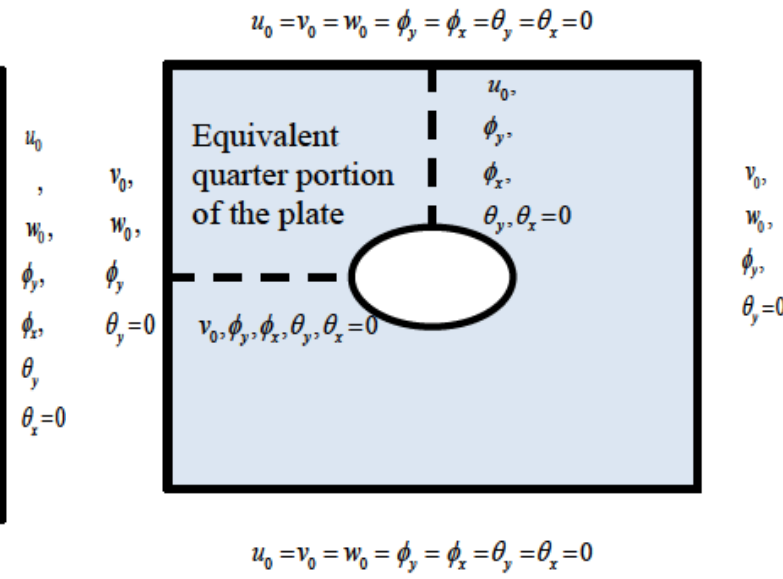

(d)

Figure 2: Boundary condition of full plate with hole and equivalent quarter portion of the plate (a) SSSS1; (b) SSSS2; (c) CCCC; (d) CSCS

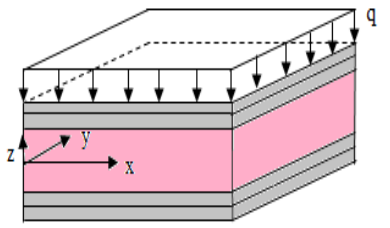

(a)

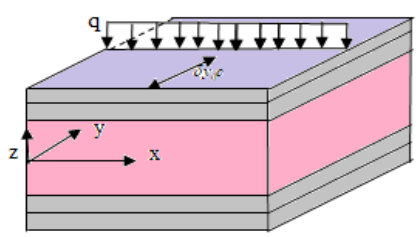

(d)

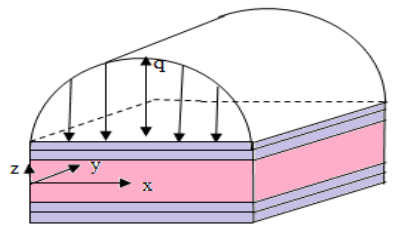

(b)

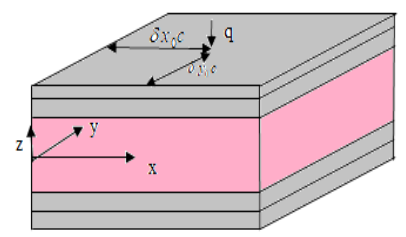

(e)

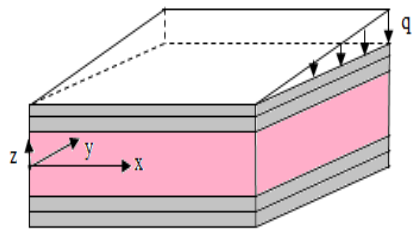

(c)

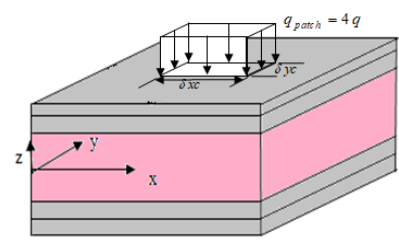

(f)

Figure 3: Effect of various types of loading on the sandwich plate for (a) uniformly distributed loading; (b) sinusoidal loading; (c) hydrostatic loading; (d) line loading; (e) point loadings; (f) patch loadings 
Sinusoidal load (SSL):

$q_{s s l}=q 0 \sin (\pi x c / a) \sin (\pi y c / a) E_{2}(h / a)^{4}$

Point load (PL):

$q_{p}=q 0 \delta\left(x c-x_{0} c\right) \delta\left(y c-y_{0} c\right)$

Hydrostatic load (HL):

$q_{\text {hyd }}=q 0(1 / 2)(x c \times y c) E_{2}(h / a)^{4}$

Line load (LL):

$q_{\text {line load }}=q 0 \delta\left(x c-x_{0} c\right) y_{0} c$

Patch load (PaL):

$q_{\text {patch }}=\left(\frac{16}{4}\right) q 0(x c \times y c) E_{2}(h / a)^{4}$

Where $q 0$ is input load parameter, q with subscript is applied load for corresponding loading conditions, $E_{2}(h / a)^{4}$ is normalization factor, $\mathrm{xc}$ and $\mathrm{yc}$ are coordinates along $\mathrm{x}$ and y-direction of the plate and $\delta\left(x c-x_{0} c\right)$ and $\delta\left(y c-y_{0} c\right)$ are midpoint coordinates at which point load is applied.

The following normalization with different loading conditions are used for the present paper.

For UDL, PL, HL, PL and PaL:

$$
\begin{aligned}
& W_{0}=w_{\max } / h \text { and } \\
& {\left[\sigma_{x}, \sigma_{y}, \tau_{x y}, \tau_{y z}, \tau_{z x}\right]=\frac{1}{q 0}\left[\sigma_{0 x}, \sigma_{0 y}, \sigma_{0 x y}, \tau_{0 y z}, \tau_{0 x z}\right]}
\end{aligned}
$$

For SSL:

$$
\begin{aligned}
& W_{0}=w_{\max }\left(100 E_{2} h^{3} / b^{4} q 0\right) \text { and } \\
& {\left[\sigma_{x}, \sigma_{y}, \tau_{x y}, \tau_{y z}, \tau_{z x}\right]} \\
& =\frac{h}{b q 0}\left[\frac{h}{b} \sigma_{0 x}, \frac{h}{b} \sigma_{0 y}, \frac{h}{b} \sigma_{0 x y}, \tau_{0 y z}, \tau_{0 x z}\right]
\end{aligned}
$$

where, $W_{0}$ and $w_{\max }$ are normalized and maximum transverse deflections respectively. The parameters $\sigma_{x}, \sigma_{y}, \tau_{x y}$, $\tau_{y z}$, and $\tau_{z x}$ are the normalized stresses for corresponding to stresses $\sigma_{0 x}, \sigma_{0 y}, \sigma_{0 x y}, \tau_{0 y z}$ and $\tau_{0 x z}$.

For the computation of results in the present work, temperature-dependent properties of reinforced composite material are considered and estimated with a micromechanical approach. The reference temperature and moisture are assumed as $21^{\circ} \mathrm{C}$ and $0 \%$ respectively. Following material properties are taken to generate some useful results.

Material-I (for micromechanical property)

$E_{f 1}=220 \times 10^{9} \mathrm{~Pa}, \quad E_{f 2}=13.79 \times 10^{9} \mathrm{~Pa}, \quad v_{f 12}=0.2$, $\alpha_{f 1}=0.99 \times 10^{-6} \mathrm{~m} /{ }^{\circ} \mathrm{C}, \quad \alpha_{f 2}=10.08 \times 10^{-6} \mathrm{~m} /{ }^{\circ} \mathrm{C}$, $v_{f 12}=0.25, \quad E_{m}=3.45 \times 10^{9} \mathrm{~Pa}, \quad v_{m}=0.35$, $\alpha_{m}=72 \times 10^{-6} \mathrm{~m} /{ }^{\circ} \mathrm{C}, \quad \beta_{m}=0.33 \mathrm{~mm} / \% \mathrm{RH}$,

$$
\beta_{f 1}=\beta_{f 2}=0 \mathrm{~mm} / \% \mathrm{RH},
$$

LCSP with face sheet as orthotropic material and core as isotropic material is considered. Properties of the core material (Qc) is given in Appendix A-3 and that of face sheet (Material -I) are calculated with the micromechanical approach as discussed in section 2.3.

Table 1 reveals convergence study for clamped edges of laminated composite square plate (0/45/-45/90) having $\mathrm{a} / \mathrm{h}=10$ for different mesh size under UDL of $q 0=100$. It is observed that the NTMD converges for $5 \times 5$ mesh size. Hence the bending analysis of the LCSP is done by considering 16 elements.

Figure 4(a-b) shows validation for linear and nonlinear NTMD of composite plate subjected to uniform pressure having $\mathrm{a} / \mathrm{h}=10$, with stacking sequence $(0 / 45 /-45 / 90)$. It is clear from the figures that the present results are in good agreement with the published results [17] for both simply supported and clamped edges conditions.

Table 1: Convergence study for transverse central deflection in bending of laminated composite sandwich plate

\begin{tabular}{ccc}
\hline Mesh density & Present result $\left(\boldsymbol{W}_{\mathbf{0}}\right)$ & Reddy [17] \\
\hline $\mathbf{3} \times \mathbf{3}$ & $\mathrm{a} / \mathrm{h}=10$ & \\
$\mathbf{4} \times \mathbf{4}$ & 0.4068 & \\
$\mathbf{5} \times 5$ & 0.3304 & 0.3000 \\
$\mathbf{6} \times 6$ & 0.3108 & \\
$\mathbf{7 \times 7}$ & 0.3347 & \\
\hline
\end{tabular}

Figure 5(a) shows validation for ratio of NTMD of solid plate to that of plate having circular cutout with diameter of hole (D) to length of plate (a) ratio (D/a) with published result [3] for CSCS boundary conditions. Figure 5(b) represents the variation of SCF with different cutout cases.

It can be observed that the present results are in good agreement with the published results. From Figure 5(b) SCF for $\sigma_{y}$ shows maximum variation with cutout cases and $\tau_{x z}$ shows least variation with same cases of cutouts.

Figure 6(a) shows a graphical representation of NTMD throughout the simply supported (S1) LCSP (0/90/C/90/0) plate with $\mathrm{a} / \mathrm{h}=10$ under the UDL of $q O=10$. There is a maximum deflection in the center of the plate considered. The NTMD along the diagonal (along cutout) of the quarter part of the plate is shown in Figure 6(b). It is clearly observed from the figure that, as we move towards the cutout from the opposite corner the NTMD get increases due to a reduction in constrains along the edge of the cutout. With the increment in cutout dimension plate gets weaken due 


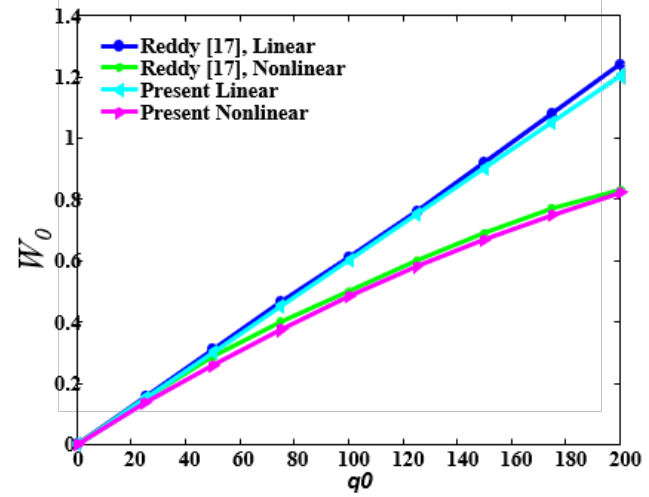

(a)

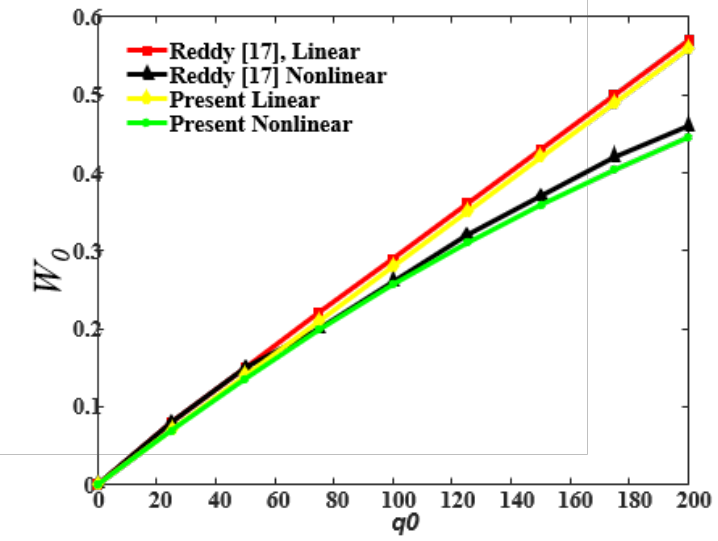

(b)

Figure 4: Validation for transverse maximum deflection of composite plate subjected to uniform pressure for a/h $=10$, with stacking sequence $0 / 45 /-45 / 90$ for (a) simply supported (SSSS2) and (b) clamped edges

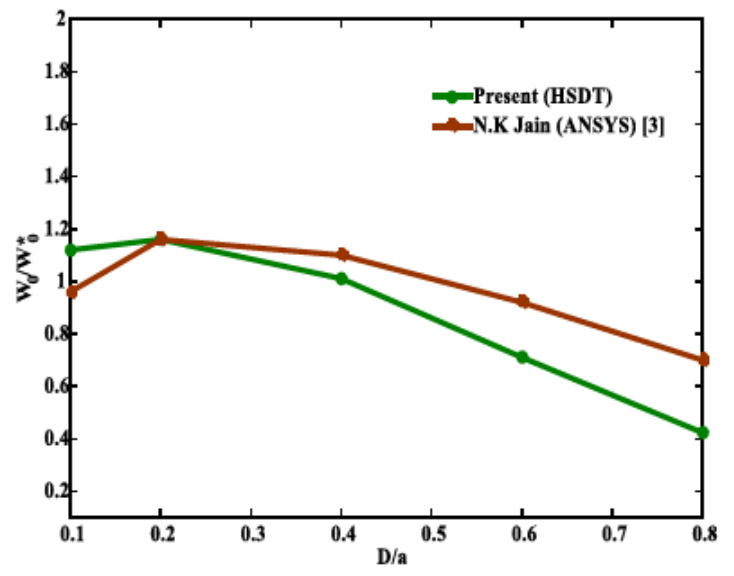

(a)

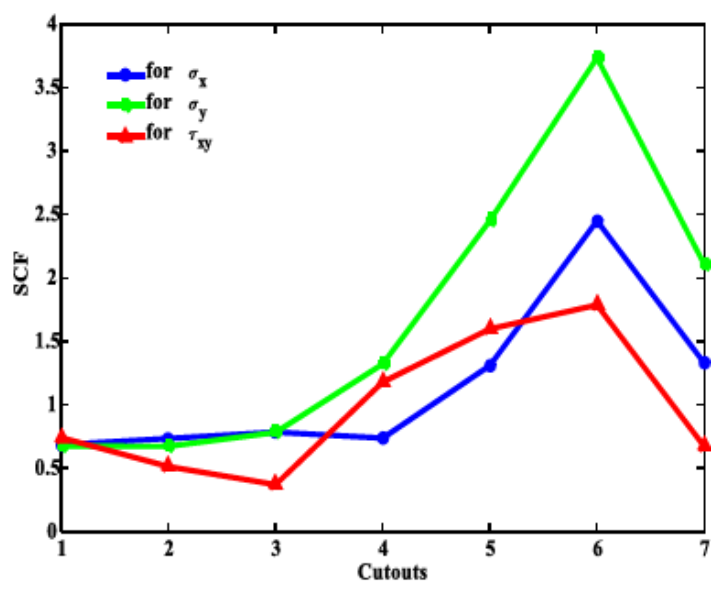

(b)

Figure 5: (a) Effect of $\mathrm{D} / \mathrm{A}$ ratio on $W_{0} / W_{0}^{\star}$ for orthotropic plate with CSCS boundary condition. (b) Effect of cutout on SCF for LCSP in simply supported conditions

to which the NTMD increases. Plate with circular hole $\left(m_{a}\right.$ $\left.=m_{i}=0.5\right)$ deflects maximum due to a larger reduction in the resisting area of the plate.

Figure $7(a-b)$ depicts the effect of cutout dimensions with fiber volume fraction on linear and non-linear NTMD of LCSP (45/-45/C/-45/45) with its all edges simplysupported (S2) for $\mathrm{a} / \mathrm{h}=20, \Delta \mathrm{T}=0, \Delta \mathrm{C}=0$ under the action of transverse UDL of $q 0=100$. It can be clearly observed that LCSP has a minimum transverse deflection for 0.6 fiber volume fraction. The plate without any cutout deflects minimum.

The plate gets weakened with cutout and increasing cutout dimension; therefore, deflection increases as the whole load is acting upon the smaller area. For cutout as $m_{a}=0.1$ and $m_{i}=0.6$ the plate shows maximum NTMD.

Figure $8(a-b)$ shows the influence of cutout dimensions with a transverse UDL on the linear and non-linear NTMD of simply supported (S2) LCSP (0/90/C/90/0), for $\mathrm{a} / \mathrm{h}=10, V_{f}=0.5, \Delta \mathrm{T}=0$, and $\Delta \mathrm{C}=0$. It can be clearly observed from the figure that, NTMD increases with increase in load. Plate without cutout shows more rigidity and minimum increment in deflection with an increase in load while plate with circular cutout and elliptical hole $\left(m_{a}=0.1, m_{i}=0.6\right)$ show maximum increment in deflection with the rise in load and gets deflected the most (approx. $40 \%$ more than plate without cutout). As cutout dimensions increase, the deflection increases due to the in- 


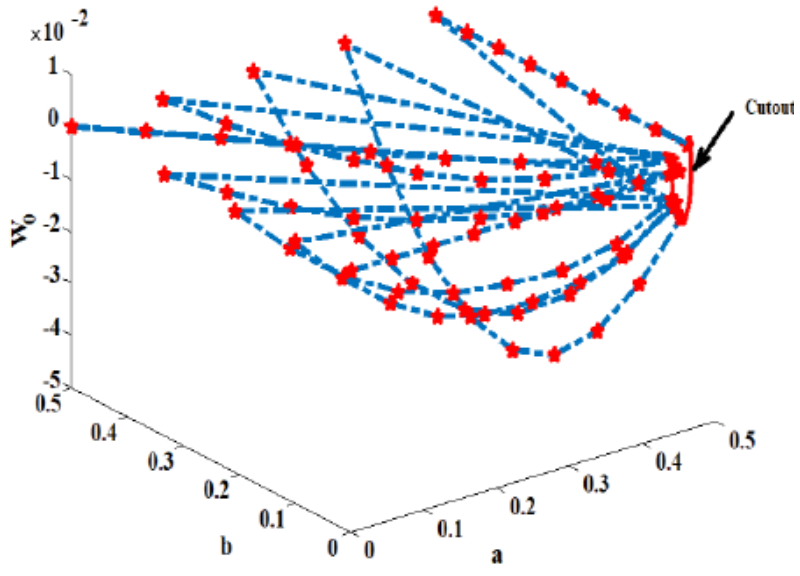

(a)

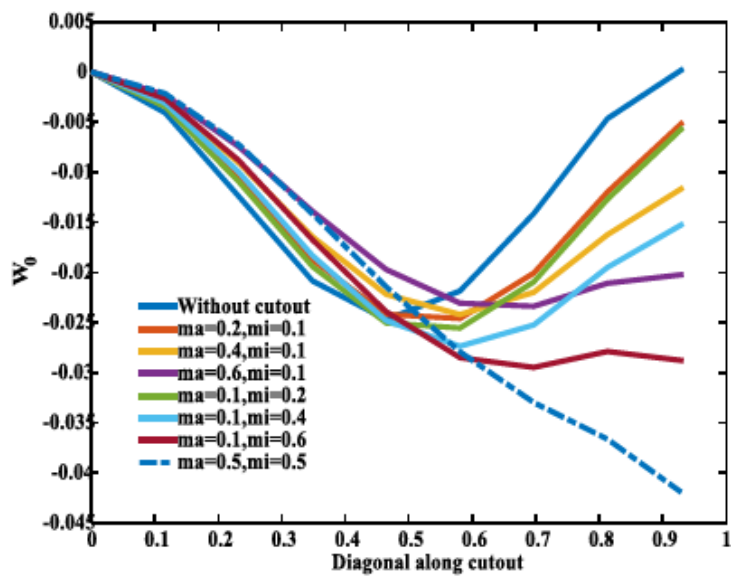

(b)

Figure 6: Transverse deflection contour for (a) the plate (b) along diagonal (along cutout) of the plate for different cutout cases

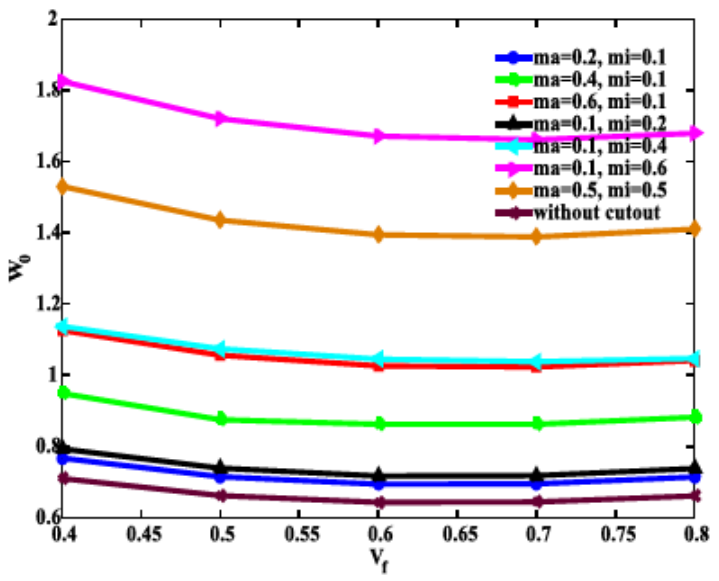

(a)

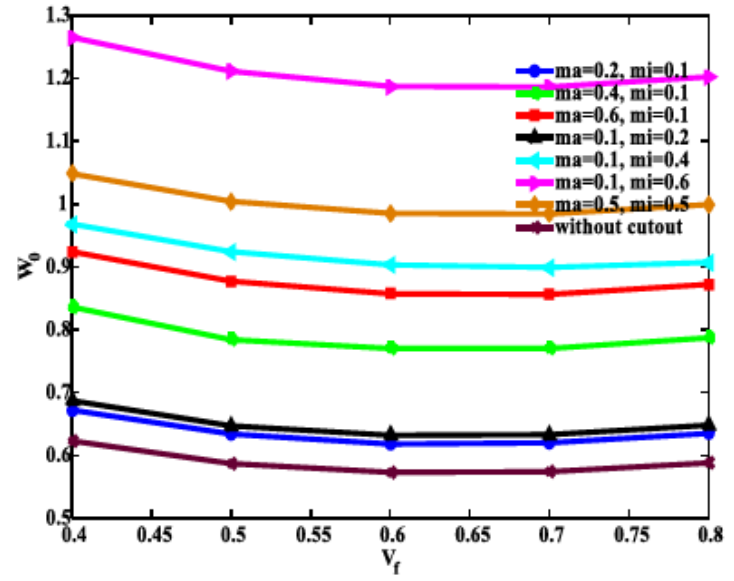

(b)

Figure 7: (a) Linear and (b) nonlinear, variation of NTMD with fiber volume fraction

crease of load intensity on the remaining reduced exposed area of the plate.

Figure 9(a-b) illustrates the effect of cutout dimensions with plate aspect ratio on the linear and non-linear NTMD of simply supported (S2) laminated (0/90/C/90/0) sandwich square plate with $\mathrm{a} / \mathrm{h}=15, V_{f}=0.5, \Delta \mathrm{T}=0$, and $\Delta \mathrm{C}=0$ when acted upon by transverse UDL of $q 0=25$. It is observed from the Figure $9(\mathrm{a}-\mathrm{b})$ that LCSP with aspect ratio, $\mathrm{b} / \mathrm{a}=1$ has least NTMD because square plates have more strength than equivalent rectangular plate under same loading condition. Increase in aspect ratio from 1 to 1.5 deflection increases severely, after $b / a=1.5$ less increment is observed.

Linear and non-linear variation of NTMD with cutout dimensions and plate span to thickness ratio $(\mathrm{a} / \mathrm{h})$ for square LCSP (0/90/C/90/0) with clamped edges under $q 0$
$=50$, having $V_{f}=0.5, \Delta \mathrm{T}=0$, and $\Delta \mathrm{C}=0$ are shown in Figures 10 (a) and 10(b), respectively. It is observed from these figures that with increasing the plate thickness ratio, the NTMD decreases because in thick plate, shear deformation and transverse elasticity are more pronounced. Plate with circular hole shows maximum deflection due to the largest cutout area and solid plate without any cutout deflect less. The figure shows that with a rise in span to thickness ratio $(\mathrm{a} / \mathrm{h})$ the NTMD lower while the effect of an increase in cutout dimensions on the same is reverse as resisting area decrease with increasing cutout dimension.

The NTMD for lower span to thickness ratio is higher than that of higher span to thickness ratio due to the same reason that, for thicker plate, transverse flexibility and shear deformation are higher. The compressibility of core 


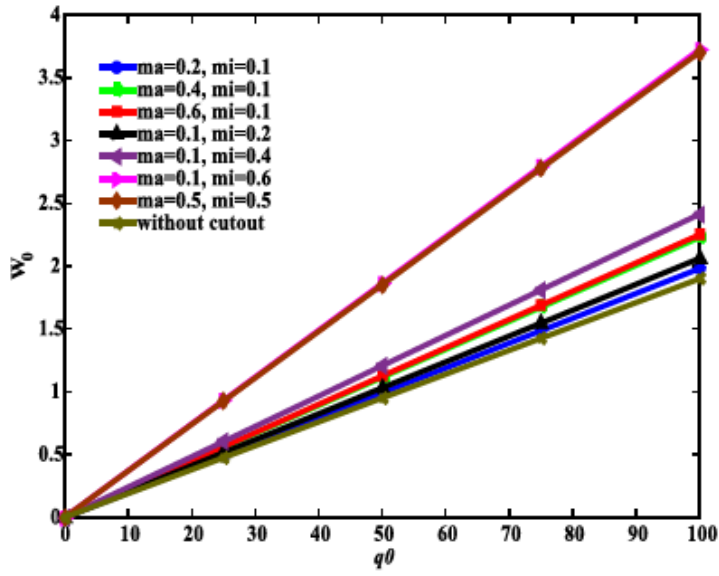

(a)

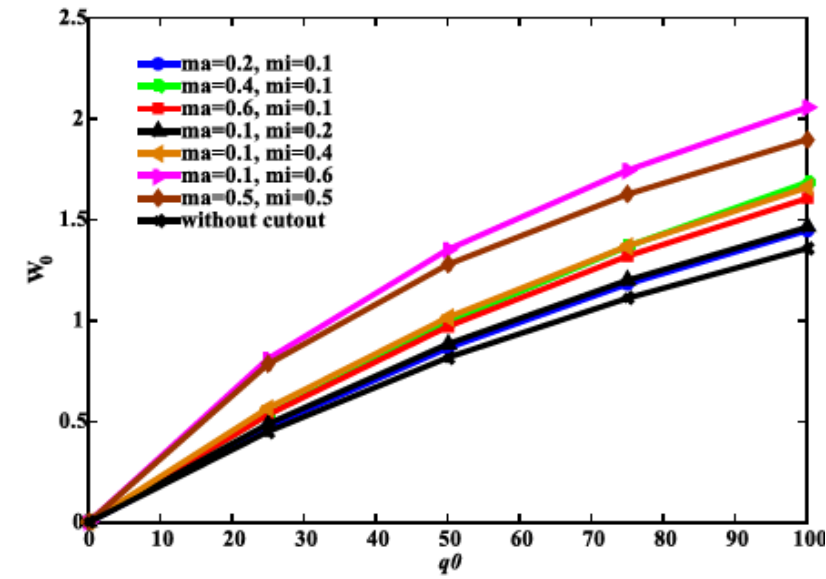

(b)

Figure 8: (a) Linear and (b) nonlinear variation of NTMD with loading of LCSP having elliptical cutout

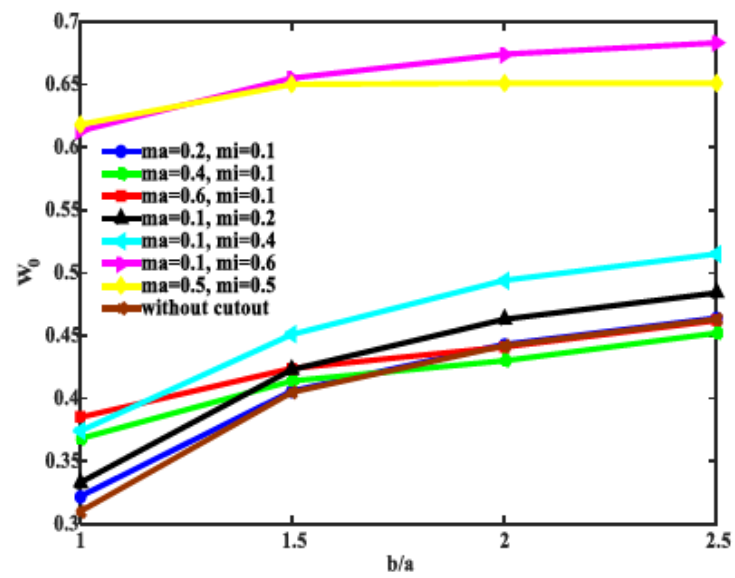

(a)

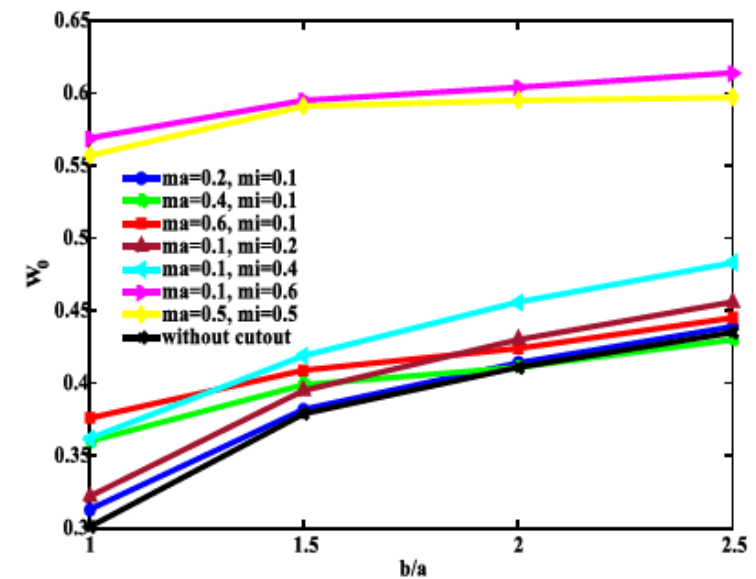

(b)

Figure 9: (a) linear and (b) nonlinear variation of NTMD with aspect ratio of plate with cutout

also plays a significant role due to the large thickness portion $(0.8 \mathrm{~h})$ of total plate thickness.

Figure 11 shows a variation of NTMD with loading conditions for square simply supported composite plate $(0 / 45 /-45 / 90)$ having $\mathrm{b} / \mathrm{a}=1, \mathrm{a} / \mathrm{h}=10$. Point or concentrated load shows maximum deflection, approximately 2.5 times more than UDL due to action on small area. Therefore, care must be taken while applying point load on the structure to avoid unwanted deformation and failure. Patch load is the second most severe loading condition and line load shows minimum deflection while SSL and HL show 3 times more NTMD than line loading.

Figure 12 depicts the trend variation of in-plane normal stress $\left(\sigma_{x}\right)$ along the thickness of simply supported (SSSS1) LCSP $(0 / \mathrm{C} / 0)$ of $\mathrm{a} / \mathrm{h}=10$, under sinusoidal loading with and without cutout. The distribution of out plane shear stress $\left(\tau_{x z}\right)$ along the transverse direction of the plate has been compared for with and without cutout along with cutout dimensions as shown in Figure 13(a-b) for the same boundary and loading conditions.

Table 2 shows that present results are in well favor of published results. The nonlinear values are written in brackets. With the increase in multiplying factor plate gets stiffer and hence shows less deflection.

Table 3 demonstrates the effect of stacking sequence and the position of core with cutouts dimension on the linear and nonlinear (in brackets) NTMD of simply supported (S2) edges LCSP and a composite plate of $\mathrm{a} / \mathrm{h}=$ $10, V_{f}=0.5, \Delta \mathrm{T}=0$, and $\Delta \mathrm{C}=0$ acted upon by transverse UDL of $q O=100$. Linear values are shown in the bracket. It is observed that there is very little effect on transverse deflection due to a change in stacking se- 


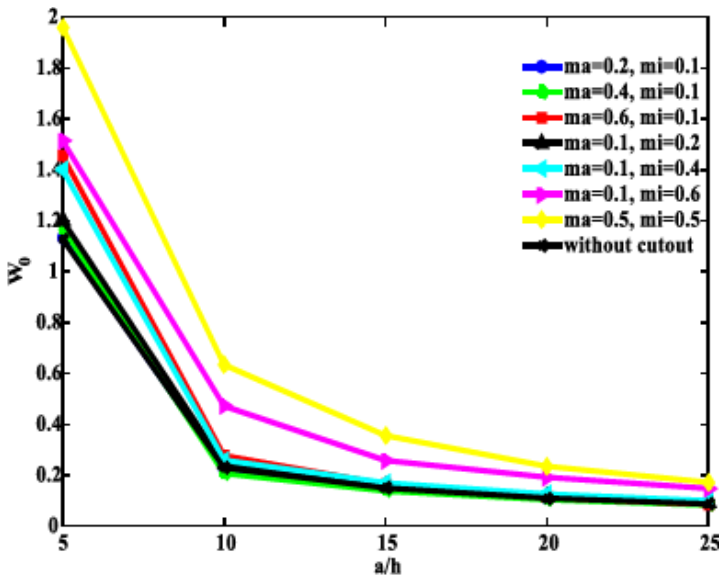

(a)

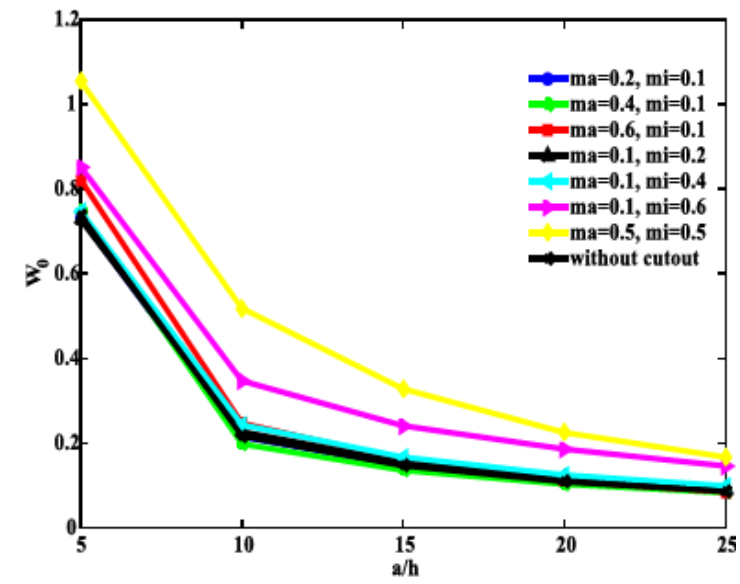

(b)

Figure 10: (a) Linear and (b) nonlinear variation of NTMD with plate span to thickness ratio

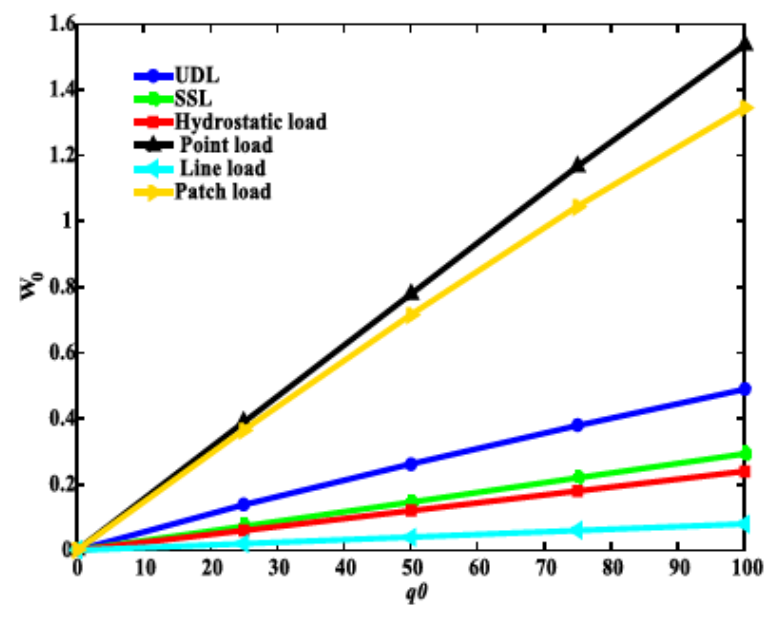

Figure 11: Variation of NTMD of LCSP under various loading conditions

quence from symmetric to antisymmetric $(0 / 90 / C / 90 / 0)$ to $(0 / 90 / C / 0 / 90)$, while the significant difference in transverse deflection has been observed with variation in core position (0/C/90/90/0) to (0/90/0/C/90). Laminated composite sandwich plate (LCSP) with circular hole shows maximum deflection about 39\% more than plate without cutout. The NTMD increases with an increase in major and minor axis radii of elliptical cutout due to the same reason as a decrease in the area upon which load acts reduces. Sandwich plate (0/C/90/90/0) shows lower deflection than composite $(0 / 90 / 90 / 0)$ plate because sandwich panels have higher transverse rigidity.

Table 4 shows the effect of cutouts dimension with a thickness of face sheet and the core of simply supported (S2) LCSP with stacking sequence $(45 /-45 / \mathrm{C} / 45 /-45)$ and $\mathrm{a} / \mathrm{h}=10, V_{f}=0.5, \Delta \mathrm{T}=0$, and $\Delta \mathrm{C}=0$ on NTMD under uni-

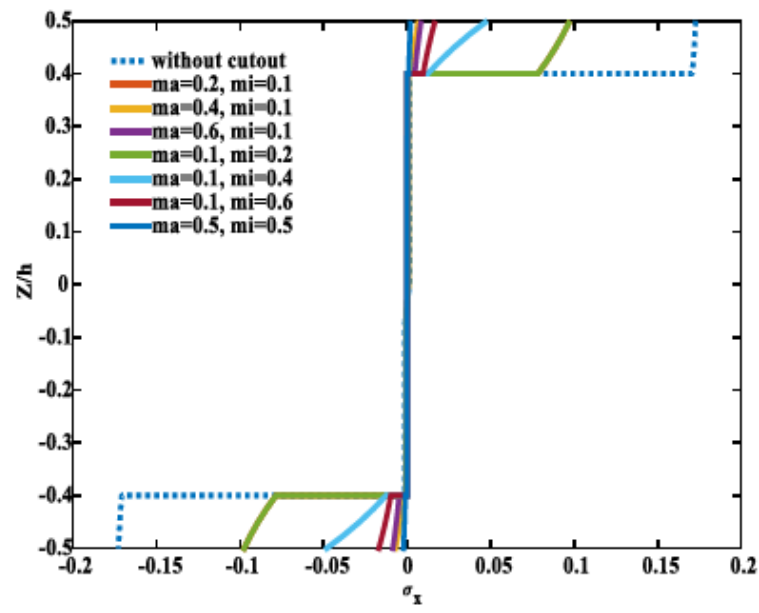

Figure 12: Variation of $\sigma_{\chi}$ for LCSP having different cutouts

formly distributed load of $q O=100$. It is clear from the table that, with an increase of face thickness $\left(h_{f}\right)$, the deflection decreases. It is because of the increase in the thickness of stiffer material (face or skin). With the increase of major and minor axis radii of the elliptical hole, deflection increases due to decrease in resisting area to the load. Plate without cutout shows minimum deflection and weakened with cutout. It is interesting that with just doubling the face sheet thickness the deflection gets reduced by $32 \%$.

Table 5 reveals the influence of fiber angle with cutout dimensions on NTMD of simply supported (S2) LCSP having $\mathrm{a} / \mathrm{h}=20, V_{f}=0.5, \Delta \mathrm{T}=0$, and $\Delta \mathrm{C}=0$ under the action of UDL of magnitude $q O=100$. It is clear from the table that the stacking sequence has a significant effect on NTMD. The deflection decreases with increase in fiber angle along principle material direction up to $45^{\circ}$ after 


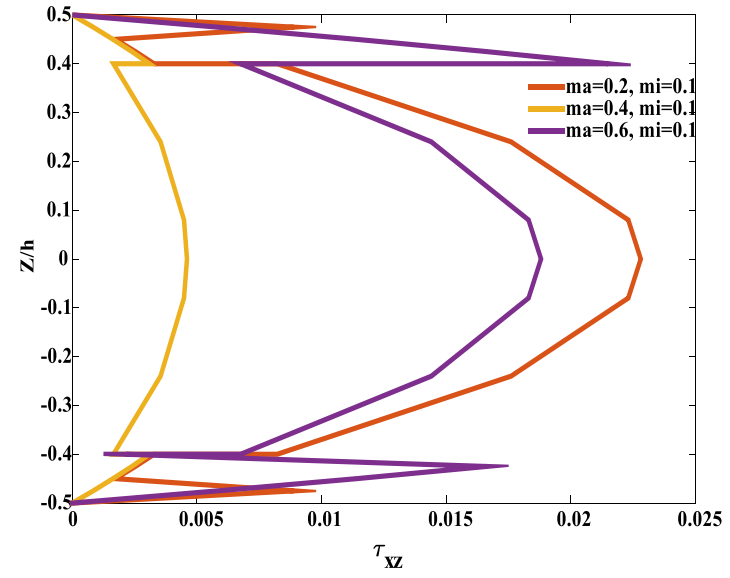

(a)

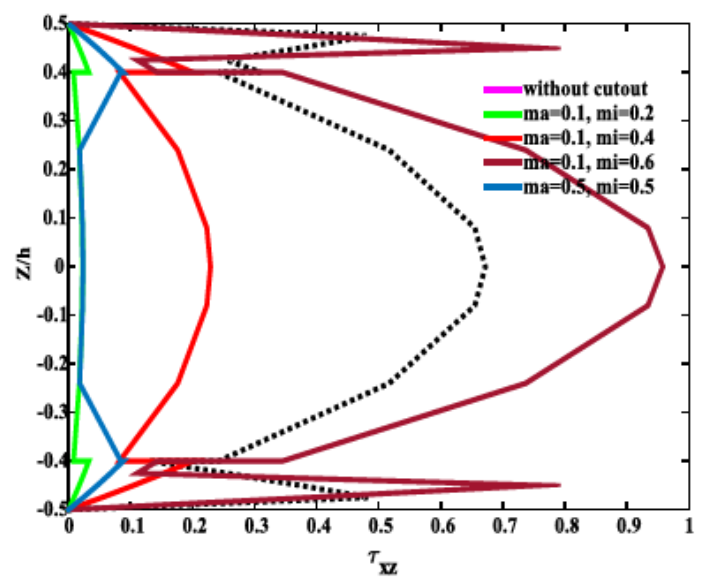

(b)

Figure 13: (a) and (b) distribution and comparison of $\tau_{x z}$ along the thickness of LCSP having different cutout

Table 2: Validation study for square sandwich plate $(0 / \mathrm{C} / 0)$ of $\mathrm{a} / \mathrm{h}=10$ with simply supported edges under uniform pressure

\begin{tabular}{|c|c|c|}
\hline $\mathbf{R}$ & Source & $w_{0}$ \\
\hline & Present & $257.24(153.081)$ \\
\hline & Exact & 258.97 \\
\hline \multirow[t]{5}{*}{5} & Ferreira [14] & 258.74 \\
\hline & Pandya and Kant [18] & 258.74 \\
\hline & Mantari et al. [22] & 256.706 \\
\hline & Present & $159.01(89.814)$ \\
\hline & Exact & 159.38 \\
\hline \multirow[t]{5}{*}{10} & Ferreira [14] & 159.402 \\
\hline & Pandya and Kant [18] & 152.33 \\
\hline & Mantari et al. [22] & 155.498 \\
\hline & Present & $121.81(63.614)$ \\
\hline & Exact & 121.72 \\
\hline \multirow[t]{3}{*}{15} & Ferreira [14] & 121.821 \\
\hline & Pandya and Kant [18] & 110.43 \\
\hline & Mantari et al. [22] & 115.919 \\
\hline
\end{tabular}

that the NTMD increases with further increment in fiber angle. Therefore, it is clear that laminates have highest NTMD with $45^{\circ}$ fiber angles. As fiber angle changes from (0/0/C/0/) to $(30 / 30 / \mathrm{C} / 30 / 30)$ NTMD reduced to $33 \%$ with further reduction in the fiber angle to $(45 / 45 / \mathrm{C} / 45 / 45)$ the deflection reduced to $42 \%$ as compared to $(0 / 0 / C / 0 / 0)$.

Table 6 shows the variation of NTMD with various support conditions and cutout dimension for laminated [45/-45/C/45/-45] sandwich square plate with a/h=10, $V_{f}$ $=0.5, \Delta \mathrm{T}=0$ and $\Delta \mathrm{C}=0$ under the action of transverse UDL of magnitude $q 0=50$. The linear values are bracket. The LCSP shows less deflection (11\% less) for SSSS (1) than SSSS (2) due to having more constrains. With all edges clamped plate shows the least deflection, about $27 \%$ less than a plate with SSSS(S1) boundary condition. With the increase in major and minor axis radii deflection increases. It is clear from the table that plate with its all edges clamped is more stable.

Table 7 shows linear and nonlinear (in brackets) variation of NTMD with cutout dimension and environmental conditions for simply supported (S2) laminated $(0 / 90 / \mathrm{C} / 90 / 0)$ sandwich square plate with $\mathrm{a} / \mathrm{h}=50$ and $V_{f}$ $=0.5$ when UDL of $q 0=50$ is applied transversally. The NTMD increases with the increase of $\Delta \mathrm{T}$ due to weaken the intermolecular bonding force. With the increment in cutout dimension NTMD increases. There is a negligible effect of $\Delta \mathrm{C}$ on the deflection while temperature has a significant influence on the same. With the increment in moisture from $\Delta \mathrm{C}=0.1$ to $\Delta \mathrm{C}=0.2$, there is very less $0.12 \%$ increment in NTMD while increasing temperature from $\Delta \mathrm{T}=$ 100 to $\Delta \mathrm{T}=150$ the NTMD increases $3 \%$ which is far more than that due to moisture.

Table 8 shows validation of NTMD for different loading conditions on square simply supported isotropic plate for $\mathrm{a} / \mathrm{h}=10$ with published results [17]. Present results are in great agreement with published one for UDL, SSL, HL and LL while satisfactory in case of point loading condition.

Table 9 demonstrates the variation of NTMD with loading conditions and cutout dimension for laminated composite sandwich square plate $(0 / 90 / C / 90 / 0)$ with clamped edges having $\mathrm{a} / \mathrm{h}=10$ acted upon by an UDL of magnitude $q O=50$. There is maximum deflection when the whole load is concentrated to a point and minimum for load acted along a line. It is clear from the table that, the plate is weakened with cutout and NTMD increase with the increase in 
Table 3: Variation of transverse central deflection of simply supported (S2) LCSP and composite plate with stacking sequences and cutouts dimensions

\begin{tabular}{lccccc}
\hline Cutouts dimension & & & \multicolumn{1}{c}{$\boldsymbol{W}_{\mathbf{0}}$} & \\
& $\mathbf{0 / 9 0 / C / 9 0 / 0}$ & $\mathbf{0 / 9 0 / C / 0 / 9 0}$ & $\mathbf{0 / C / 9 0 / 9 0 / 0}$ & $\mathbf{0 / 9 0 / 0 / C / 9 0}$ & $\mathbf{0 / 9 0 / 9 0 / 0}$ \\
\hline$m_{a}=0.2$ & 1.447 & 1.400 & 0.867 & 1.854 & 0.991 \\
$m_{i}=0.1$ & $(1.981)$ & $(1.920)$ & $(1.054)$ & $(3.550)$ & $(1.178)$ \\
$m_{a}=0.4$ & 1.686 & 1.633 & 0.991 & 2.046 & 1.175 \\
$m_{i}=0.1$ & $(2.229)$ & $(2.168)$ & $(1.176)$ & $(3.613)$ & $(1.361)$ \\
$m_{a}=0.6$ & 1.606 & 1.561 & 1.018 & 2.101 & 1.176 \\
$m_{i}=0.1$ & $(2.251)$ & $(2.209)$ & $(1.295)$ & $(4.992)$ & $(1.380)$ \\
$m_{a}=0.1$ & 1.463 & 1.415 & 0.880 & 1.824 & 1.001 \\
$m_{i}=0.2$ & $(2.062)$ & $(1.995)$ & $(1.088)$ & $(3.641)$ & $(1.236)$ \\
$m_{a}=0.1$ & 1.660 & 1.585 & 1.098 & 1.877 & 1.458 \\
$m_{i}=0.4$ & $(2.414)$ & $(2.303)$ & $(1.551)$ & $(3.764)$ & $(2.026)$ \\
$m_{a}=0.1$ & 2.056 & 1.961 & 1.098 & 2.100 & 1.829 \\
$m_{i}=0.6$ & $(3.726)$ & $(3.468)$ & $(1.551)$ & $(4.107)$ & $(3.772)$ \\
$m_{a}=0.5$ & 1.898 & 1.833 & 1.136 & 2.103 & 1.528 \\
$m_{i}=0.5$ & $(3.703)$ & $(3.555)$ & $(1.872)$ & $(4.236)$ & $(2.869)$ \\
Without cutout & 1.358 & 1.321 & 0.842 & 1.757 & 0.913 \\
& $(1.900)$ & $(1.842)$ & $(1.039)$ & $(3.501)$ & $(1.118)$ \\
\hline
\end{tabular}

Table 4: Effect of cutout dimensions with thickness of face and core on NTMD of simply supported (S2) laminated sandwich square plate $(45 /-45 / C / 45 /-45)$

\begin{tabular}{ccccc}
\hline Cutouts dimension & \multicolumn{3}{c}{$\boldsymbol{W}_{\mathbf{0}}$} \\
\cline { 2 - 5 } & $\begin{array}{c}\boldsymbol{h}_{\boldsymbol{f}} \mathbf{= 0 . 0 5} \mathbf{h}, \\
\boldsymbol{h}_{\boldsymbol{c}}=\mathbf{0 . 8 h}\end{array}$ & $\begin{array}{c}\boldsymbol{h}_{\boldsymbol{f}}=\mathbf{0 . 1} \mathbf{h}, \\
\boldsymbol{h}_{\boldsymbol{c}}=\mathbf{0 . 6 h}\end{array}$ & $\begin{array}{c}\boldsymbol{h}_{\boldsymbol{f}}=\mathbf{0 . 1 5 h}, \\
\boldsymbol{h}_{\boldsymbol{c}}=\mathbf{0 . 4 h}\end{array}$ & $\begin{array}{c}\boldsymbol{h}_{\boldsymbol{f}}=\mathbf{0 . 2} \mathbf{h}, \\
\boldsymbol{h}_{\boldsymbol{c}}=\mathbf{0 . 2 h}\end{array}$ \\
\hline$m_{a}=0.2$ & 1.049 & 0.702 & 0.568 & 0.506 \\
$m_{i}=0.1$ & $(1.355)$ & $(0.833)$ & $(0.662)$ & $(0.597)$ \\
$m_{a}=0.4$ & 1.141 & 0.769 & 0.626 & 0.562 \\
$m_{i}=0.1$ & $(1.465)$ & $(0.900)$ & $(0.716)$ & $(0.646)$ \\
$m_{a}=0.6$ & 1.208 & 0.820 & 0.671 & 0.605 \\
$m_{i}=0.1$ & $(1.571)$ & $(0.965)$ & $(0.769)$ & $(0.694)$ \\
$m_{a}=0.1$ & 1.111 & 0.778 & 0.568 & 0.581 \\
$m_{i}=0.2$ & $(1.741)$ & $(1.068)$ & $(0.662)$ & $(0.766)$ \\
$m_{a}=0.1$ & 1.202 & 0.828 & 0.682 & 0.615 \\
$m_{i}=0.4$ & $(1.687)$ & $(1.036)$ & $(0.825)$ & $(0.744)$ \\
$m_{a}=0.1$ & 1.232 & 0.843 & 0.691 & 0.624 \\
$m_{i}=0.6$ & $(1.642)$ & $(1.009)$ & $(0.804)$ & $(0.726)$ \\
$m_{a}=0.5$ & 0.970 & 0.667 & 0.549 & 0.493 \\
$m_{i}=0.5$ & $(1.444)$ & $(0.888)$ & $(0.709)$ & $(0.644)$ \\
Without cutout & 1.023 & 0.631 & 0.501 & 0.475 \\
& $(1.489)$ & $(0.876)$ & $(0.632)$ & $(0.502)$ \\
\hline
\end{tabular}

cutout dimension with $13 \%$ as compared to the plate without any cutout. Point load is almost 2.5 and 16 times sever than UDL and line load, respectively. Therefore, care must be taken for the structure acted upon by point load. Patch load is applied on the four, central element (except ele- ment adjacent to boundary of the plate). The whole UDL is concentrated on these four elements which causes second most severe condition.

Table 10 represents the impact of cutout dimensions with various stresses the NTMD of simply supported (S2) 
Table 5: Effect of stacking sequence with cutout dimensions on simply supported (S2) laminated sandwich square plate

\begin{tabular}{lccccc}
\hline Cutouts dimension & \multicolumn{5}{c}{$\boldsymbol{W}_{\mathbf{0}}$} \\
\cline { 2 - 6 } & $\mathbf{0 / 0 / C} / \mathbf{0} / \mathbf{0}$ & $\mathbf{3 0 / 3 0 / C / 3 0 / 3 0}$ & $\mathbf{4 5 / 4 5 / C / 4 5 / 4 5}$ & $\mathbf{6 0 / 6 0 / C} / \mathbf{6 0} / \mathbf{6 0}$ & $\mathbf{9 0 / 9 0 / C / 9 0 / 9 0}$ \\
\hline$m_{a}=0.2$ & 1.591 & 1.055 & 0.907 & 0.9339 & 1.176 \\
$m_{i}=0.1$ & $(1.773)$ & $(1.232)$ & $(1.063)$ & $(1.083)$ & $(1.358)$ \\
$m_{a}=0.4$ & 1.910 & 1.137 & 1.009 & 0.974 & 1.295 \\
$m_{i}=0.1$ & $(2.127)$ & $(1.300)$ & $(1.157)$ & $(1.1016)$ & $(1.751)$ \\
$m_{a}=0.6$ & 1.876 & 1.235 & 1.176 & 1.132 & 2.081 \\
$m_{i}=0.1$ & $(2.120)$ & $(1.467)$ & $(1.503)$ & $(1.899)$ & $(3.739)$ \\
$m_{a}=0.1$ & 1.877 & 1.207 & 0.924 & 0.930 & 1.192 \\
$m_{i}=0.2$ & $(2.122)$ & $(1.344)$ & $(1.106)$ & $(1.098)$ & $(1.387)$ \\
$m_{a}=0.1$ & 3.243 & 2.271 & 1.787 & 1.287 & 1.213 \\
$m_{i}=0.4$ & $(4.673)$ & $(3.123)$ & $(2.315)$ & $(1.552)$ & $(1.422)$ \\
$m_{a}=0.1$ & 3.771 & 2.843 & 2.286 & 1.874 & 1.219 \\
$m_{i}=0.6$ & $(8.833)$ & $(6.020)$ & $(4.438)$ & $(3.047)$ & $(1.858)$ \\
$m_{a}=0.5$ & 2.674 & 2.249 & 1.907 & 1.441 & 1.942 \\
$m_{i}=0.5$ & $(5.333)$ & $(3.735)$ & $(3.073)$ & $(2.233)$ & $(3.877)$ \\
Without cutout & 1.361 & 1.025 & 0.888 & 0.868 & 1.167 \\
& $(1.575)$ & $(1.210)$ & $(1.053)$ & $(1.025)$ & $(1.346)$ \\
\hline
\end{tabular}

Table 6: Effect cutout dimensions with various support conditions on the NTMD of laminated (45/-45/C/45/-45) sandwich square plate

\begin{tabular}{ccccc}
\hline Cutouts dimension & \multicolumn{3}{c}{$\boldsymbol{W}_{\mathbf{0}}$} \\
\cline { 2 - 5 } & SSSS (2) & SSSS (1) & CSCS & CCCC \\
\hline$m_{a}=0.2$ & 0.679 & 0.571 & 0.278 & 0.226 \\
$m_{i}=0.1$ & $(0.746)$ & $(0.746)$ & $(0.310)$ & $(0.242)$ \\
$m_{a}=0.4$ & 0.774 & 0.630 & 0.261 & 0.206 \\
$m_{i}=0.1$ & $(0.862)$ & $(0.862)$ & $(0.291)$ & $(0.218)$ \\
$m_{a}=0.6$ & 0.822 & 0.636 & 0.344 & 0.245 \\
$m_{i}=0.1$ & $(0.969)$ & $(0.969)$ & $(0.463)$ & $(0.286)$ \\
$m_{a}=0.1$ & 0.742 & 0.644 & 0.286 & 0.237 \\
$m_{i}=0.2$ & $(0.819)$ & $(0.819)$ & $(0.322)$ & $(0.256)$ \\
$m_{a}=0.1$ & 1.208 & 0.957 & 0.323 & 0.289 \\
$m_{i}=0.4$ & $(1.432)$ & $(1.432)$ & $(0.364)$ & $(0.318)$ \\
$m_{a}=0.1$ & 1.551 & 1.137 & 0.526 & 0.458 \\
$m_{i}=0.6$ & $(2.216)$ & $(2.216)$ & $(0.637)$ & $(0.607)$ \\
$m_{a}=0.5$ & 1.098 & 0.805 & 0.480 & 0.412 \\
$m_{i}=0.5$ & $(1.466)$ & $(1.466)$ & $(0.643)$ & $(0.518)$ \\
Without cutout & 0.627 & 0.540 & 0.278 & 0.227 \\
& $(0.692)$ & $(0.692)$ & $(0.311)$ & $(0.244)$ \\
\hline
\end{tabular}

LCSP $(0 / 90 / C / 90 / 0)$ under SSL with $q 0=100$, for $\mathrm{a} / \mathrm{h}=10$ by considering micromechanical approach for face sheet material property with Material-I. It can be observed from the table that with cutout dimensions NTMD and stresses vary severely. For a plate with an elliptical hole, as major and minor axis radii of the hole increases deflection and stresses increases. NTMD of a plate without cutout increases by $20 \%$ when an elliptical hole of $m_{a}=0.2$ and $m_{i}$
$=0.1$ is made in the center of the plate and then drastically increased by approximately 10 times of that of the plate without any cutout. This is due to the severity in the cutout edge which has no constrains of boundary conditions. 
Table 7: Effect cutout dimensions with environmental condition on the central deflection of simply supported (S2) laminated (0/90/C/90/0) sandwich square plate

\begin{tabular}{|c|c|c|c|c|c|}
\hline \multirow[t]{2}{*}{ Cutouts dimension } & \multicolumn{5}{|c|}{$W_{0}$} \\
\hline & $\begin{array}{l}\Delta \mathrm{T}=0 \\
\Delta \mathrm{C}=0\end{array}$ & $\begin{array}{l}\Delta \mathrm{T}=100 \\
\Delta \mathrm{C}=0.1\end{array}$ & $\begin{array}{l}\Delta \mathrm{T}=150, \\
\Delta \mathrm{C}=0.1\end{array}$ & $\begin{array}{l}\Delta \mathrm{T}=100, \\
\Delta \mathrm{C}=0.2\end{array}$ & $\begin{array}{l}\Delta \mathrm{T}=150, \\
\Delta \mathrm{C}=0.2\end{array}$ \\
\hline$m_{a}=0.2$ & 0.4964 & 0.5173 & 0.5372 & 0.5179 & 0.5384 \\
\hline$m_{i}=0.1$ & $(0.5158)$ & $(0.5385)$ & $(0.5602)$ & $(0.5392)$ & $(0.5616)$ \\
\hline$m_{a}=0.4$ & 0.5548 & 0.5774 & 0.5987 & 0.5781 & 0.6000 \\
\hline$m_{i}=0.1$ & $(0.5798)$ & $(0.6045)$ & $(0.6280)$ & $(0.6053)$ & $(0.6294)$ \\
\hline$m_{a}=0.6$ & 0.6005 & 0.6249 & 0.6479 & 0.6256 & 0.6493 \\
\hline$m_{i}=0.1$ & $(0.6327)$ & $(0.6601)$ & $(0.6860)$ & $(0.6609)$ & $(0.6876)$ \\
\hline$m_{a}=0.1$ & 0.6260 & 0.6516 & 0.6760 & 0.6524 & 0.6775 \\
\hline$m_{i}=0.2$ & $(0.6737)$ & $(0.7042)$ & $(0.7335)$ & $(0.7051)$ & $(0.7353)$ \\
\hline$m_{a}=0.1$ & 0.6298 & 0.6545 & 0.6779 & 0.6552 & 0.6793 \\
\hline$m_{i}=0.4$ & $(0.6720)$ & $(0.7006)$ & $(0.7278)$ & $(0.7015)$ & $(0.7295)$ \\
\hline$m_{a}=0.1$ & 0.6244 & 0.6493 & 0.6728 & 0.6501 & 0.6742 \\
\hline$m_{i}=0.6$ & $(0.6626)$ & $(0.6912)$ & $(0.7181)$ & $(0.6920)$ & $(0.7198)$ \\
\hline$m_{a}=0.5$ & 0.5875 & 0.6133 & 0.6380 & 0.6141 & 0.6395 \\
\hline$m_{i}=0.5$ & $(0.6379)$ & $(0.6700)$ & $(0.7011)$ & $(0.6710)$ & $(0.7030)$ \\
\hline \multirow[t]{2}{*}{ Without cutout } & 0.4834 & 0.5045 & 0.5271 & 0.5085 & 0.5237 \\
\hline & $(0.5084)$ & $(0.5276)$ & $(0.5547)$ & $(0.5214)$ & $(0.5543)$ \\
\hline
\end{tabular}

Table 8: Validation of displacements for different loading conditions on square simply supported isotropic plate

\begin{tabular}{llllll}
\hline Loadings & Uniformly Distributed Load & Sinusoidal Load & Hydrostatic Load & Line Load & Point Load \\
\hline Reddy [43] & 0.0444 & 0.0280 & 0.0222 & 0.0074 & 0.1266 \\
Present & 0.0480 & 0.0293 & 0.0240 & 0.0080 & 0.1555 \\
\hline
\end{tabular}

Table 9: Variation of NTMD with loading conditions for laminated composite sandwich square plate with clamped edges

\begin{tabular}{|c|c|c|c|c|c|c|}
\hline \multirow[t]{2}{*}{ Cutouts dimension } & \multicolumn{6}{|c|}{$w_{0}$} \\
\hline & UDL & SSL & Point Load & Hydrostatic Load & Line Load & Patch Load \\
\hline$m_{a}=0.2$ & 0.4112 & 0.2319 & 1.0174 & 0.1912 & 0.0645 & 0.4124 \\
\hline \multicolumn{7}{|l|}{$m_{i}=0.1$} \\
\hline$m_{a}=0.4$ & 0.4314 & 0.2579 & 1.1050 & 0.2127 & 0.0718 & 0.4592 \\
\hline \multicolumn{7}{|l|}{$m_{i}=0.1$} \\
\hline$m_{a}=0.6$ & 0.4462 & 0.2806 & 1.1718 & 0.2315 & 0.0782 & 0.5759 \\
\hline \multicolumn{7}{|l|}{$m_{i}=0.1$} \\
\hline$m_{a}=0.1$ & 0.4435 & 0.2859 & 1.0670 & 0.2376 & 0.0815 & 0.6536 \\
\hline \multicolumn{7}{|l|}{$m_{i}=0.2$} \\
\hline$m_{a}=0.1$ & 0.4590 & 0.2923 & 1.1390 & 0.2401 & 0.0804 & 0.6872 \\
\hline \multicolumn{7}{|l|}{$m_{i}=0.4$} \\
\hline$m_{a}=0.1$ & 0.4629 & 0.2924 & 1.1849 & 0.2415 & 0.0817 & 0.7131 \\
\hline \multicolumn{7}{|l|}{$m_{i}=0.6$} \\
\hline$m_{a}=0.5$ & 0.3856 & 0.2461 & 0.9843 & 0.2040 & 0.0696 & 0.4334 \\
\hline \multicolumn{7}{|l|}{$m_{i}=0.5$} \\
\hline Without cutout & 0.3625 & 0.2313 & 0.964 & 0.2005 & 0.0613 & 0.4030 \\
\hline
\end{tabular}


Table 10: Effect of cutout dimensions with various stresses the central deflection of simply supported (S2) laminated (0/90/C/90/0) sandwich square plate under SSL

\begin{tabular}{|c|c|c|c|c|c|}
\hline Cutouts dimension & $\begin{array}{c}W_{0} \\
(a / 2, b / 2,0)\end{array}$ & $\begin{array}{c}\sigma_{x} \\
(a / 2, b / 2, h / 2)\end{array}$ & $\begin{array}{c}\sigma_{y} \\
(a / 2, b / 2, h / 4)\end{array}$ & $\begin{array}{c}\tau_{y z} \\
(a / 2,0,0)\end{array}$ & $\begin{array}{c}\sigma_{x z} \\
(0, b / 2,0)\end{array}$ \\
\hline$m_{a}=0.2$ & 2.045 & 0.020 & 0.0184 & 0.0069 & 0.0018 \\
\hline \multicolumn{6}{|l|}{$m_{i}=0.1$} \\
\hline$m_{a}=0.4$ & 16.49 & 0.065 & 0.0548 & 0.0202 & 0.0703 \\
\hline \multicolumn{6}{|l|}{$m_{i}=0.1$} \\
\hline$m_{a}=0.6$ & 15.75 & 0.064 & 0.0434 & 0.0591 & 0.0669 \\
\hline \multicolumn{6}{|l|}{$m_{i}=0.1$} \\
\hline$m_{a}=0.1$ & 2.162 & 0.031 & 0.0213 & 0.0051 & 0.0043 \\
\hline \multicolumn{6}{|l|}{$m_{i}=0.2$} \\
\hline$m_{a}=0.1$ & 15.75 & 0.072 & 0.0614 & 0.0363 & 0.0203 \\
\hline \multicolumn{6}{|l|}{$m_{i}=0.4$} \\
\hline$m_{a}=0.1$ & 16.84 & 0.075 & 0.0734 & 0.0636 & 0.0324 \\
\hline \multicolumn{6}{|l|}{$m_{i}=0.6$} \\
\hline$m_{a}=0.5$ & 8.234 & 0.0563 & 0.238 & 0.510 & 0.449 \\
\hline \multicolumn{6}{|l|}{$m_{i}=0.5$} \\
\hline Without cutout & 1.692 & 1.023 & 1.014 & 0.156 & 0.156 \\
\hline
\end{tabular}

\section{Conclusions}

This paper presents flexural behavior of LCSPs with cutout subjected to different types of loading under various supporting condition with influence of ecological conditions. Some outcomes of the present work can be concluded as,

- With increasing the major and minor axis radii one at a time keeping another constant the deflection increases due to decrease in the resisting area acted upon by load.

- Variation in stacking sequences with the same ply angle has less effect on the NTMD while the position of core affects significantly and the LCSP with the core as the middle layer shows minimum deflection.

- With an increase in the thickness of stiffer material (face sheet) the plate goes stiffer and shows less NTMD.

- The NTMD of LCSP decreases with an increase in span to plate thickness ratio up to $\mathrm{a} / \mathrm{h}=20$ then after approaches a constant value because plate gets rigid enough to resist further deflection when thickness increases up to a certain value.

- The square plate shows less NTMD than a rectangular plate with and without cutout. NTMD increase with the increase in $\mathrm{a} / \mathrm{b}$ ratio, initially at a faster rate and after $\mathrm{a} / \mathrm{b}=2$ for the rectangular plate, comparatively with a slower rate.
- Plate with all edges clamped shows less NTMD due to a large number of constrains.

- Up to $V_{f}=0.7$ of fiber volume fraction, NTMD decreases with increase in $V_{f}$ fraction, after that with a further increment of $V_{f}$ the deflection increases because of reduction in bonding surface area between fiber and matrix material of composite.

- Temperature affects proportionally and more significantly than moisture to NTMD.

\section{References}

[1] Paul T.K., Rao K.M., Stress analysis around circular holes in FRP laminates under transverse load, Comp. Struct., 1989, 33, 923 937.

[2] Paul T.K., Rao K.M., Finite element evaluation of stress concentration factor of thick laminated plates under transverse loading, Comp. Struct., 1993, 48, 311-317.

[3] Jain N.K., Analysis of stress concertation and deflection in isotropic and orthotropic rectangular plates with maximum circular hole under transverse loading, Int. J. Mech. Mechatr. Eng., 2009, 3, 1513-1519.

[4] Xiwu X., Liandxing S., Xuqi, F., Stress concentration of finite composite laminates weakened by multiple elliptical holes, Int. J. Solid Struct., 1995, 32, 3001-3014.

[5] Rzayyig A.Y., Effect of cutouts on the behavior of clamped rectangular plates, Anbar J. Eng. Sci., 2011, 2, 45-59.

[6] Ukadgaonker V.G., Rao D.K.N., A general solution for stresses around holes in symmetric laminates under inplane loading, Compos. Struct., 2000, 49, 339-354. 
[7] Toubal L., Karama M., Lorrain B., Stress concentration in a circular hole in composite plate, Compos. Struct., 2005, 68, 31-36.

[8] Patel N.P., Sharma D.S., Bending of composite plate weakened by square hole, Int. J. Mech. Sci., 2015, 94, 131-139.

[9] Priyadharshani S.A., Prasad A.M., Sundaravadivelu R., Analysis of GFRP stiffened composite plates with rectangular cutout, Compos. Struct., 2017, 169, 42-51.

[10] Sai Ram K.S., Babu T.S., Study of bending of laminated composite shells. Part II: shells with a cutout, Compos. Struct., 2001, 51, 117-126.

[11] Chaudhuri P.B., Mitra A., Sahoo S., Deflection, forces and moments of composite stiffened hyper shells with cutout, Mater. Today: Proc., 2017, 4, 9718-9722.

[12] Ghannadpour S.A.M., Mehrparvar M., Energy effect removal technique to model circular/elliptical holes in relatively thick composite plates under in-plane compressive load, Compos. Struct, 2018, 202, 1032-1041.

[13] Zhou J. Li, Z., Chen J., Damage identification method based on continuous wavelet transform and mode shapes for composite laminates with cutouts, Compos. Struct., 2018, 191, 12-23.

[14] Ferreira A.J.M., Analysis of Composite Plates Using a layerwise theory and multiquadric discretization, Mech. Adv. Mater. Struct., 2005, 12, 99-112.

[15] Ghosh A.K., Dey S.S., A simple element for the analysis of laminated plates, Compos. Struct., 1990, 44, 585-596.

[16] Cho M., Parmerter R.R., An efficient higher-order plate theory for laminated composites, Compos. Struct., 1992, 20, 113-123.

[17] Putcha N.S., Ruddy J.N., A refined mixed shear flexible finite element for the non-linear analysis of laminated plates, Comp. Struct., 1986, 22, 529-538.

[18] Pandya B.N., Kant T., Higher-order shear deformable theories for flexure of sandwich plates-finite element evaluations, Int. J. Solids Struct., 1988, 24, 167-1286.

[19] Grover N., Maiti D.K., Singh B.N., A new inverse hyperbolic shear deformation theory for static and buckling response of laminate composite and sandwich plates, Compos. Struct., 2013, 95, 667675.

[20] Grover N., Singh B.N., Maiti D.K., Analytical and finite element modeling of laminated composite and sandwich plates: An assessment of a new shear deformation theory for free vibration response, Int. J. Mech. Sci., 2013, 67, 89-99.

[21] Lal A., Kulkarni N.M., Siddaramaiah V.H., Stochastic hygrothermo-mechanically induced non-linear static analysis of piezoelectric elastically support sandwich plate using secant function based shear deformation theory (SFSDT), Int. J. Comput. Mater. Sci. Eng., 2016, 6, 16500201-46.

[22] Mantari J.L., Oktem A.S., Soares C.G., A new trigonometric shear deformation theory for isotropic, laminated composite and sandwich plates, Int. J. Solids Struct., 2012, 49, 43-53.

[23] Reddy J.N., An evaluation of equivalent-single-layer and layer wise theories of composite laminates, Compos. Struct., 1993, 25, 21-35.

[24] Sayyad S.A., Ghugal Y.M., Naik N.S., Bending analysis of laminated composite and sandwich beams according to refined trigonometric beam theory, Curved and Layer. Struct, 2015, 2, 279-289.

[25] Sheikh A.H., Chakrabarti A., A new plate bending element based on higher-order shear deformation, 2003, 39, 883-903.

[26] Touratier M., An efficient standard plate theory, Int. J. Eng. Sci., 1991, 29, 901-916.
[27] Srikanth G., Kumar A, Post buckling response and failure of symmetric laminates under uniform temperature rise, Compos. Struct., 2003, 59, 109-118.

[28] Maiti D.K., Sinha P.K., Bending, free vibration and impact responses of thick laminated composite plates, Comp. Struct., 1996, 5, 115-129.

[29] Carrera E., Theories and finite elements for multilayered, anisotropic, composite plates and shells, Archiv. Comput. Meth. Eng., 2002, 9, 87-140.

[30] Carrera E., Historical review of zig-zag theories for multilayered plates and shells, Appl. Mech. Rev., 2003, 56, 65-75.

[31] Carrera E., Valvano S., A variable kinematic shell formulation applied to thermal stress of laminated structures, J. Therm. Stress., 2016, 40, 803-827.

[32] Carrera E., Valvano S., Filippi M., Classical, higher-order, zigzag and variable kinematic shell elements for the analysis of composite multilayered structures, Europ. J. Mech. / A Solids, 2018, 72, 97-110.

[33] Tornabene F., Fantuzzi N., Bacciocchi M., Linear Static Behavior of Damaged Laminated Composite Plates and Shell, Materials, 2017, 10, 1-51.

[34] Tornabenea F., Brischettob S., 3D capability of refined GDQ models for the bending analysis of composite and sandwich plates, spherical and doubly-curved shells, Thin-Walled Struct., 2018, 129, 94-124.

[35] Tornabene F., Fantuzzi N., Bacciocchi M., Foam core composite sandwich plates and shells with variable stiffness: Effect of the curvilinear fiber path on the modal response, J. Sandwich Struct. Mater., 2017, 21, 320-365.

[36] Woodward B., Kashtalyan M., 3D elasticity analysis of sandwich panels with graded core under distributed and concentrated loadings, Int. J. Mech. Sci., 2011, 53, 872-885.

[37] Upadhyay A.K., Pandey R., Shukla K.K., Non-linear flexural response of laminated composite plates under hygro-thermomechanical loading, Commun. Non-linear Sci Numer. Simulat., 2010, 15, 2634-2650.

[38] Kumar R., Patil H.S., Lal A., Hygrothermoelastic buckling response of laminated composite plates with random system properties macro-mechanical and micromechanical model, J. Aerosp. Eng., 2012, 28, 04014123-18.

[39] Lal A., Kulkarni N., Singh B.N., Stochastic thermal post-buckling response of elastically supported laminated piezoelectric composite plate using micromechanical approach, Curved and Layer. Struct., 2015, 2, 331-350.

[40] Pandit M.K., Sheikh A.H., Singh B.N., An improved higher order zigzag theory for the static analysis of laminated sandwich plate with a soft core, Finite Elem. An. Design, 2008, 44, 602-610.

[41] Hadjiloizi D. A., Kalamkarov A. L., Metti Ch., Georgiades A. V., Analysis of Smart Piezo-Magneto-Thermo-Elastic Composite and Reinforced Plates: Part I - Model Development, Curved and Layer. Struct., 2014, 1, 11-31.

[42] Hadjiloizi D. A., Kalamkarov A. L., Metti Ch., Georgiades A. V., Analysis of Smart Piezo-Magneto-Thermo-Elastic Composite and Reinforced Plates: Part II - Applications, Curved and Layer. Struct., 2014, 1, 32-58.

[43] Reddy J.N., Theory and analysis of elastic plates and shells. $2^{\text {nd }}$ ed. Boca Raton: CRC Press, 2007. 


\section{Appendix:}

$$
\begin{aligned}
& {[\mathrm{T}]=\left[\begin{array}{ccccccccccccc}
1 & 0 & 0 & z & 0 & 0 & z^{3} & 0 & 0 & 0 & 0 & 0 & 0 \\
0 & 1 & 0 & 0 & z & 0 & 0 & z^{3} & 0 & 0 & 0 & 0 & 0 \\
0 & 0 & 1 & 0 & 0 & z & 0 & 0 & z^{3} & 0 & 0 & 0 & 0 \\
0 & 0 & 0 & 0 & 0 & 0 & 0 & 0 & 0 & 1 & 0 & z^{2} & 0 \\
0 & 0 & 0 & 0 & 0 & 0 & 0 & 0 & 0 & 0 & 1 & 0 & z^{2}
\end{array}\right],} \\
& \left\{\overline{\varepsilon_{0}}\right\}=\left\{\begin{array}{l}
\varepsilon_{1}^{0} \\
\varepsilon_{2}^{0} \\
\varepsilon_{6}^{0} \\
k_{1}^{0} \\
k_{2}^{0} \\
k_{6}^{0} \\
k_{1}^{2} \\
k_{2}^{2} \\
k_{6}^{2} \\
\varepsilon_{4}^{0} \\
\varepsilon_{5}^{0} \\
k_{4}^{2} \\
k_{5}^{2}
\end{array}\right\}=\left[\begin{array}{ccccccc}
\partial / \partial x & 0 & 0 & 0 & 0 & 0 & 0 \\
0 & \partial / \partial y & 0 & 0 & 0 & 0 & 0 \\
\partial / \partial y & \partial / \partial x & 0 & 0 & 0 & 0 & 0 \\
0 & 0 & 0 & 0 & -\partial / \partial x & 0 & C 1 \partial / \partial x \\
0 & 0 & 0 & -\partial / \partial y & 0 & C 1 \partial / \partial y & 0 \\
0 & 0 & 0 & -\partial / \partial x & -\partial / \partial y & C 1 \partial / \partial x & C 1 \partial / \partial y \\
0 & 0 & 0 & 0 & 0 & 0 & \partial / \partial x \\
0 & 0 & 0 & 0 & 0 & \partial / \partial y & 0 \\
0 & 0 & 0 & 0 & 0 & \partial / \partial x & \partial / \partial y \\
0 & 0 & \partial / \partial y & -C 2 & 0 & 0 & 0 \\
0 & 0 & \partial / \partial x & 0 & -C 2 & 0 & 0 \\
0 & 0 & 0 & 0 & 0 & C 2 & 0 \\
0 & 0 & 0 & 0 & 0 & 0 & C 2
\end{array}\right]\left\{\begin{array}{c}
u_{0} \\
v_{0} \\
w_{0} \\
\phi_{y} \\
\phi_{x} \\
\theta_{y} \\
\theta_{x}
\end{array}\right\}=[L]\{\vee\}, \\
& {\left[Q_{c}\right]=10^{9} \times\left[\begin{array}{ccccc}
0.999781 & 0.231192 & 0 & 0 & 0 \\
0.231192 & 0.524886 & 0 & 0 & 0 \\
0 & 0 & 0.26810 & 0 & 0 \\
0 & 0 & 0 & 0.266810 & 0 \\
0 & 0 & 0 & 0 & 0.15991
\end{array}\right]} \\
& D=\sum_{k=1}^{N L} \int_{z_{k-1}}^{z_{k}}[T]\left[\overline{Q_{i j}}\right][T] d z=\left[\begin{array}{ccccc}
{\left[A_{1 i j}\right]} & {\left[B_{i j}\right]} & {\left[E_{i j}\right]} & 0 & 0 \\
{\left[B_{i j}\right]} & {\left[C_{1 i j}\right]} & {\left[F_{1 i j}\right]} & 0 & 0 \\
{\left[E_{i j}\right]} & {\left[F_{1 i j}\right]} & {\left[H_{i j}\right]} & 0 & 0 \\
0 & 0 & 0 & {\left[A_{2 i j}\right]} & {\left[C_{2 i j}\right]} \\
0 & 0 & 0 & {\left[C_{2 i j}\right]} & {\left[F_{2 i j}\right]}
\end{array}\right]
\end{aligned}
$$

with

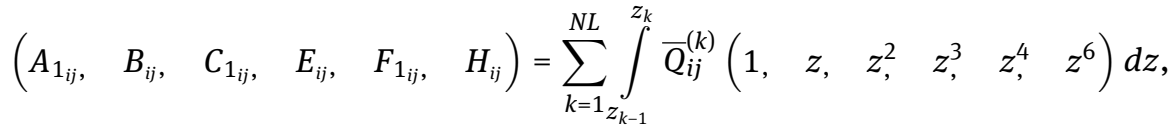

For $i, j=1,2,6$,

$$
\left\{\overline{\varepsilon_{L}}\right\}=[L]\{\Lambda\},
$$

For $i, j=4,5$,

$$
D_{3}=\left[\begin{array}{cc}
A_{1 i j} & 0 \\
B_{i j} & 0 \\
E_{i j} & 0 \\
0 & A_{2 i j} \\
0 & C_{2 i j}
\end{array}\right], \quad D_{4}=\left[\begin{array}{ccccc}
A_{1 i j} & B_{i j} & E_{i j} & 0 & 0 \\
0 & 0 & 0 & A_{2 i j} & C_{2 i j}
\end{array}\right], \quad D_{5}=\left[\begin{array}{cc}
A_{1 i j} & 0 \\
0 & A_{2 i j}
\end{array}\right]
$$




$$
[T]=\left[\begin{array}{ccccccccccccc}
1 & 0 & 0 & z & 0 & 0 & g(z) & 0 & 0 & 0 & 0 & 0 & 0 \\
0 & 1 & 0 & 0 & z & 0 & 0 & g(z) & 0 & 0 & 0 & 0 & 0 \\
0 & 0 & 1 & 0 & 0 & z & 0 & 0 & g(z) & 0 & 0 & 0 & 0 \\
0 & 0 & 0 & 0 & 0 & 0 & 0 & 0 & 0 & 1 & 0 & g^{\prime}(z) & 0 \\
0 & 0 & 0 & 0 & 0 & 0 & 0 & 0 & 0 & 0 & 1 & 0 & g^{\prime}(z)
\end{array}\right]
$$

